\title{
Simulation of QUENCH-15 and Preliminary Pre-Test Predictions for QUENCH-19
}

Fuel Cycle Research \& Development Advanced Fuels Campaign

LJ Ott

KR Robb

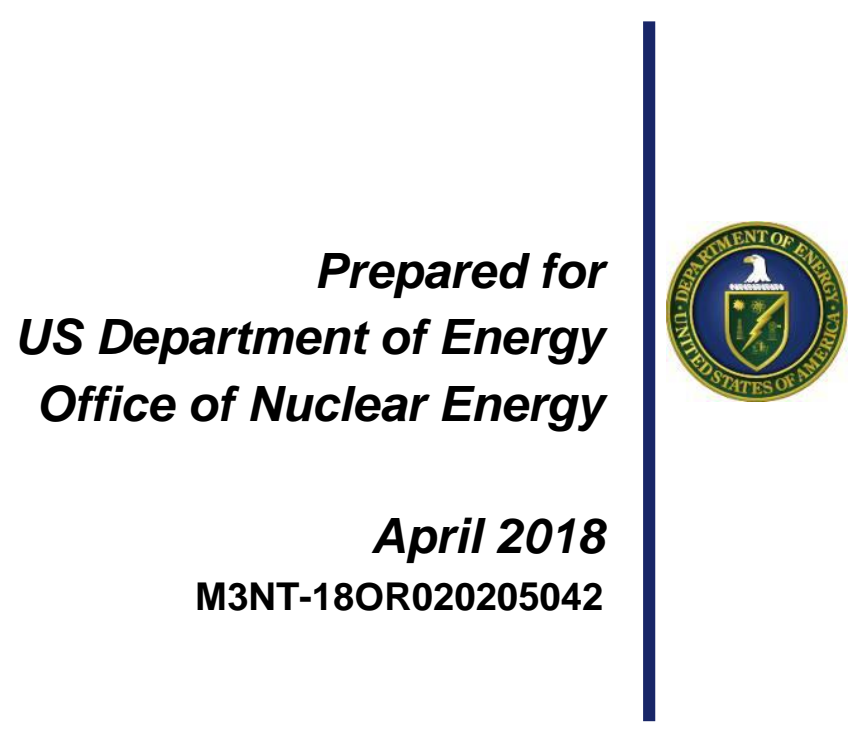

Approved for public release. Distribution is unlimited. 


\section{DISCLAIMER}

This information was prepared as an account of work sponsored by an agency of the U.S. Government. Neither the U.S. Government nor any agency thereof, nor any of their employees, makes any warranty, expressed or implied, or assumes any legal liability or responsibility for the accuracy, completeness, or usefulness, of any information, apparatus, product, or process disclosed, or represents that its use would not infringe privately owned rights. References herein to any specific commercial product, process, or service by trade name, trade mark, manufacturer, or otherwise, does not necessarily constitute or imply its endorsement, recommendation, or favoring by the U.S. Government or any agency thereof. The views and opinions of authors expressed herein do not necessarily state or reflect those of the U.S. Government or any agency thereof. 
ORNL/SPR-2018/832

Revision 0

\title{
Simulation of QUENCH-15 and Preliminary Pre-Test Predictions for QUENCH-19
}

\author{
LJ Ott \\ KR Robb
}

April 2018

Prepared by

OAK RIDGE NATIONAL LABORATORY

Oak Ridge, TN 37831-6283

managed by

UT-BATTELLE, LLC

for the

US DEPARTMENT OF ENERGY

under contract DE-AC05-00OR22725 
INTENTIONALLY BLANK 


\begin{abstract}
Iron chromium aluminum $(\mathrm{FeCrAl})$ alloys have been developed at Oak Ridge National Laboratory for use as advanced fuel cladding for light water reactors (LWRs). In contrast to the zirconium-based alloys employed today, FeCrAl has slower oxidation kinetics and higher strength. A test (QUENCH-19) at Karlsruhe Institute of Technology's QUENCH facility is planned to examine and demonstrate the performance of $\mathrm{FeCrAl}$ cladding under postulated accident conditions. This test will replicate the previous QUENCH-15 test but will use FeCrAl instead of zirconium-based materials. During these tests, a small bundle of fuel rod simulators is electrically heated in a steam and argon environment. Temperature history, oxidation thickness, and in-situ hydrogen generation are the primary measurements of interest.

The CORA boiling water reactor (BWR) code (CORA/BWR) was developed and used in the 1980s and 1990s to simulate BWR bundle degradation during the CORA test series. A modified version of the CORA/BWR code, named CORA/BWR-QUENCH, has been developed to model the QUENCH test facility. The CORA/BWR-QUENCH code was used to model the QUENCH-15 test, which tested zirconium-based materials. The code predictions and test data were found to be in good agreement. Using the same boundary conditions as the QUENCH-15 test, the code was then used to model the planned QUENCH-19 test using FeCrAl cladding, shroud, and spacer grids. The simulation predicts the peak cladding temperature to be $1,620 \mathrm{~K}\left(\sim 1,347^{\circ} \mathrm{C}\right)$ for QUENCH-19, which is significantly lower than temperature observed during QUENCH-15 with the zirconium-based alloy. The predicted hydrogen generation is also significantly lower for the FeCrAl clad QUENCH-19 as compared to QUENCH-15: $\sim 1.7 \mathrm{~g}$ versus $\sim 48.8 \mathrm{~g}$. These results align with expectations given the much slower oxidation kinetics of $\mathrm{FeCrAl}$ alloys.
\end{abstract}


INTENTIONALLY BLANK 


\section{CONTENTS}

ABSTRACT

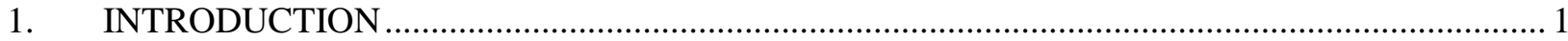

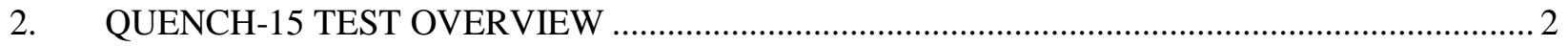

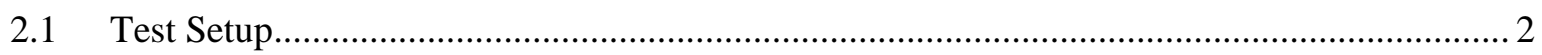

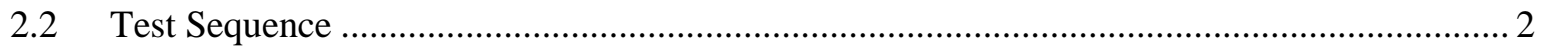

2.3 QUENCH-15 Initial and Boundary Conditions ........................................................ 2

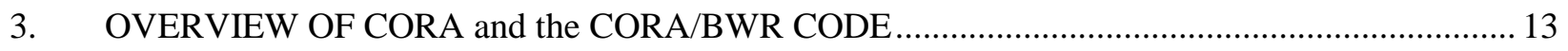

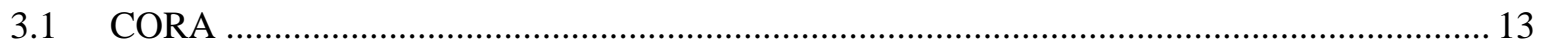

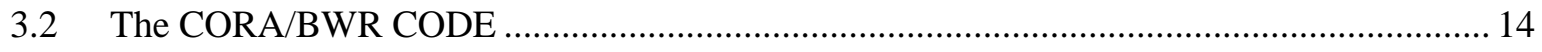

4. MODELING QUENCH TESTS AND QUENCH-15 ANALYSIS ............................................ 20

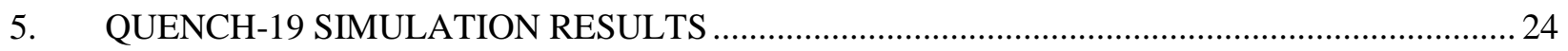

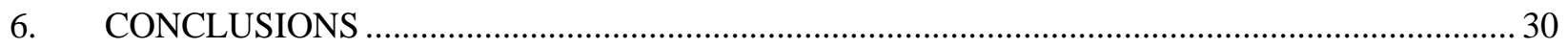

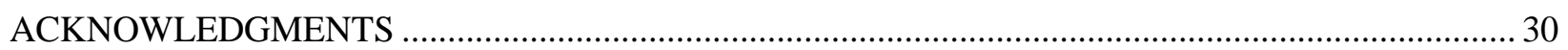

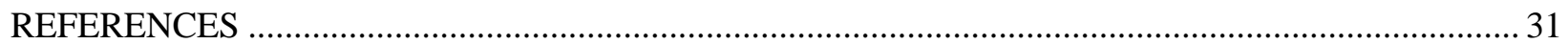

\section{FIGURES}

Figure 1 QUENCH-15 bundle cross section and rod numbering scheme (Fig. 5 of Ref. 3)...................... 4

Figure 2 QUENCH-15 test section cross section with flow lines (Fig. 4 of Ref. 3) ..................................5

Figure 3 QUENCH-15 structural axial temperature readings vs level (and simplified curves)

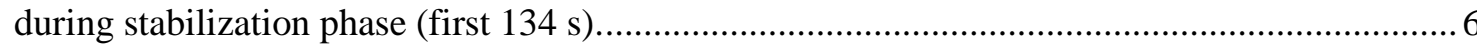

Figure 4 QUENCH-15 outer shroud (TCl) axial temperature readings vs level (and simplified curves) during stabilization phase of experiment (first $134 \mathrm{~s}$ ) ............................................... 7

Figure 5 QUENCH-15 inlet argon flow rate (and simplified curves) throughout the experiment (FM-401) 8

Figure 6 QUENCH-15 inlet steam flow rate (and simplified curves) throughout the experiment (FM-205)

Figure 7 QUENCH-15 bundle inlet fluid temperature (and simplified curves) throughout the experiment. 10

Figure 8 QUENCH-15 bundle inlet fluid pressure (and simplified curves) throughout the experiment. .11

Figure 9 QUENCH-15 core gross electric power. 12 
Figure 10 BWR fuel assembly configuration and the representative CORA test bundle configuration.

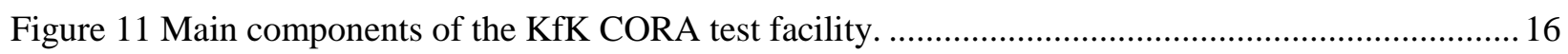

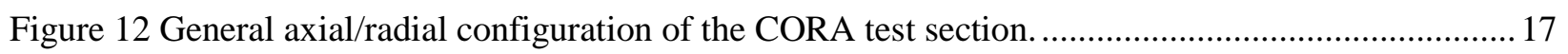

Figure 13 Quarter section of BWR test section modeled by the CORA/BWR code................................ 17

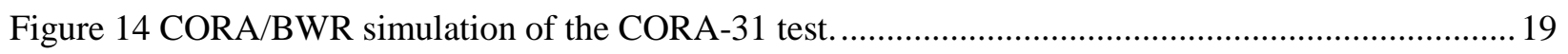

Figure 15 CORA/BWR-QUENCH simulation results for the 450 and $650 \mathrm{~mm}$ levels..........................21

Figure 16 CORA/BWR-QUENCH simulation results for the 750 and $850 \mathrm{~mm}$ levels..........................22

Figure 17 CORA/BWR-QUENCH simulation results for the $950 \mathrm{~mm}$ level. ........................................2

Figure 18 CORA/BWR-QUENCH simulation results for the integrated hydrogen core outlet flow.........23

Figure 19 Comparison of advanced Fe-based alloys' steam oxidation rate with $\mathrm{Zr}$ alloys [15]................25

Figure 20 CORA/BWR-QUENCH simulation results for the $450 \mathrm{~mm}$ level in QUENCH-19................25

Figure 21 CORA/BWR-QUENCH simulation results for the 650 and $750 \mathrm{~mm}$ levels in

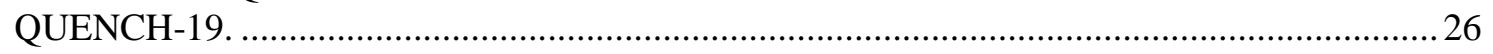

Figure 22 CORA/BWR-QUENCH simulation results for the 850 and $950 \mathrm{~mm}$ levels in

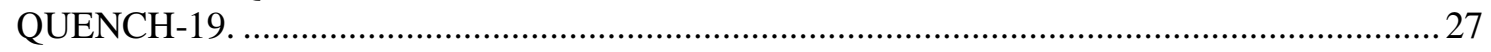

Figure 23 CORA/BWR-QUENCH simulation results for the 850 and $950 \mathrm{~mm}$ levels in

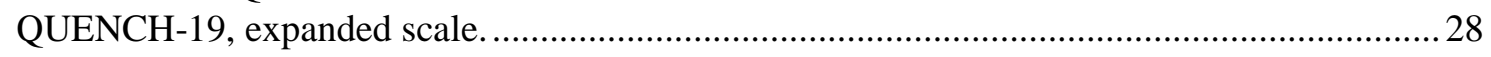

Figure 24 CORA/BWR-QUENCH simulations results for hydrogen generation in QUENCH-19...........29

\section{TABLES}

Table 1 CORA BWR test matrix. 14 


\section{Simulation of QUENCH-15 and Preliminary Pre-Test Predictions for QUENCH-19 \\ 1. INTRODUCTION}

Iron chromium aluminum ( $\mathrm{FeCrAl}$ ) alloys have been developed at Oak Ridge National Laboratory (ORNL) for use as advanced fuel cladding for light water reactors (LWRs). In contrast to the zirconiumbased alloys employed today, $\mathrm{FeCrAl}$ has slower oxidation kinetics and higher strength. During design basis or postulated LWR accidents, the reduced oxidation kinetics of $\mathrm{FeCrAl}$ provide additional time margin for recovery actions. Currently, FeCrAl lead test rods are being irradiated in a commercial reactor, and testing at additional installations is planned for the near future.

The Karlsruhe Institute of Technology's (KIT) QUENCH test facility [1, 2] investigates the performance of fuel cladding during design basis and beyond design basis accidents. Specifically, the effects of reflood on the bundle degradation are studied. The test facility includes a bundle with 21-31 electrically heated fuel rod simulators with a heated length of approximately $1 \mathrm{~m}$. The bundle is subjected to a prescribed series of power and/or temperature conditions. The tests are concluded by cooling the bundles with steam or quenching with liquid water. The in-situ temperature history, rod leak detection, and hydrogen generation, as well as the post-test examination of cladding oxidation and general bundle degradation, are the major data obtained from the tests. Since 1996, 17 QUENCH tests have been conducted and are described in the literature [1].

A QUENCH test-QUENCH-19-is planned to investigate the performance of FeCrAl cladding under accident conditions. QUENCH-19 will follow the same conditions that were used for QUENCH-15, which was conducted with ZIRLO ${ }^{\mathrm{TM}}$ cladding and is described in Section 2. By replicating the same test conditions, QUENCH-19 will provide the data needed for direct comparison between the performance of $\mathrm{ZIRLO}^{\mathrm{TM}}$ and FeCrAl cladding under similar conditions.

This report provides preliminary pre-test calculations for QUENCH-19. The test is simulated using a modified version of the CORALBWR code [7] specifically developed and validated at ORNL to model the CORA boiling water reactor (BWR) test series [14] conducted at KIT (then Kernforschungszentrum Karlsruhe $[\mathrm{KfK}])$. As the predecessor program to QUENCH, CORA also investigated the performance of LWR bundles during simulated accident conditions. Overviews of the CORA program and the ORNLdeveloped CORA/BWR code are given in Section 3.

The CORA and QUENCH test facilities and test sections are significantly different, so modifications to the CORA/BWR code were required. To validate the code's use for modeling the QUENCH test geometry and conditions, the QUENCH-15 test was also simulated and compared against the test results. These results are presented in Section 4.

The modeling requirements for QUENCH-19 and the simulation results are given in Section 5, with concluding observations made in Section 6. 


\section{QUENCH-15 TEST OVERVIEW}

The following section summarizes the test geometry, conditions, and execution of the QUENCH-15 test. The detailed report by KIT provides a thorough description of the QUENCH-15 test [3].

QUENCH-19 is a planned replication of QUENCH-15 except that structural materials (cladding, spacers, and test section shroud liner) will be made of $\mathrm{FeCrAl}$ (Fe-13Cr-6Al wt\%).

\subsection{Test Setup}

The bundle consists of 24 heated rods with ZIRLO ${ }^{\mathrm{TM}}$ cladding (labeled as "Zry" in Figure 1). Each rod has an outside diameter of $9.5 \mathrm{~mm}$. The fuel rod simulators have a central tungsten heater surrounded by annular $\mathrm{ZrO}_{2}$ pellets. The bundle's heated length is $1,024 \mathrm{~mm}$. The rods are held in place by five Zircaloy-4 grid spacers. Thermocouples are attached to the outer cladding surface at a total of 41 locations. The thermocouples are distributed over 17 discrete axial locations and each rod can have 0-5 thermocouples.

Four instrumented tubes (indicated by white circles in Figure 1) with thermocouples and four removable rods (indicated by black circles in Figure 1) are around the periphery of the heated rods. These eight rods do not contain heaters. The removable rods can be withdrawn during the test to provide a snapshot of oxidation data. Three of the removable rods and three of the instrumented tubes are made of Zircaloy-4. The other removable rod and instrumented tube are made of E110, a Russian zirconiumbased alloy. Note, in Figure 1, "Zry" indicates zirconium-based alloy is used.

The bundle is surrounded by a cylindrical zirconium 702 shroud (see Figure 1 and Figure 2). Outside the shroud there is a layer of $\mathrm{ZrO}_{2}$ fiber insulation, and the final outside layer is an argon-cooled jacket. The bundle is located inside a larger containment vessel.

A mixture of steam and argon is introduced into the lower plenum of the test section, flowing upward through the test section. The argon, reaction products (primarily hydrogen), and the remnant steam flow out of the test section containment to the measuring devices, a condenser, and the collection devices.

\subsection{Test Sequence}

The test sequence includes five phases. During the first four phases, $3.45 \mathrm{~g} / \mathrm{s}$ argon and $3.5 \mathrm{~g} / \mathrm{s}$ steam at approximately $718 \mathrm{~K}$ are injected, flowing up through the bundle. In the first phase, the bundle is heated to approximately $850 \mathrm{~K}$. The bundle is held at that temperature while the system stabilizes and while facility checks are performed. During the second phase, the bundle is heated to approximately 1,470 $\mathrm{K}$ (peak temperature). To reach this temperature, the bundle is operated at approximately $11.5 \mathrm{~kW}$. During the next pre-oxidation phase, the bundle is held at the $1,470 \mathrm{~K}$ peak temperature for approximately $2,800 \mathrm{~s}$. During the fourth phase, the bundle is subjected to transient heating by increasing the bundle power at $5.9 \mathrm{~W} / \mathrm{s}$. The peak cladding temperature is increased from approximately $1,470 \mathrm{~K}$ to $2,150 \mathrm{~K}$ in approximately $1,120 \mathrm{~s}$. In the final phase, the bundle is quenched by an injection of room temperature water into the lower plenum of the test section. A fast $(1 \mathrm{~kg} / \mathrm{s})$ injection of 4 liters is initially injected, filling the lower plenum of the test setup. This is followed by a slower injection of approximately $48 \mathrm{~g} / \mathrm{s}$ of water to quench the bundle. During this phase, the bundle power is reduced to $4.4 \mathrm{~kW}$, approximating a representative decay heat level, and then to zero power after approximately $300 \mathrm{~s}$ of decay simulation.

\subsection{QUENCH-15 Initial and Boundary Conditions}

According to data provided by KIT, [3], during the stabilization phase (the first $135 \mathrm{~s}$ of the test), the test section thermally stabilizes at the axial profiles shown in Figure 3. The outside of the test section's thermal insulation is shown in 
Figure 4. In Figure 3, there is a distinct radial gradient within the core: the red curve (Figure 3) represents rods 1-4 (Figure 1), and the orange curve represents rods 5-16, and the yellow curve represents rods 1724, while the green curve represents the inner shroud zirconium liner. These structural temperatures are used to initialize the code's model temperatures.

Additional data required for model boundary conditions are the flow rates of the argon and steam from the test section inlet, as well as the corresponding inlet fluid temperature and pressure (Figure 5 through Figure 8). The driving force for the experiment - the fuel rod simulator's electrical power (Figure 9) — provide the remaining test section boundary conditions. The blue curves in Figure 5 through Figure 9 are used in the code input.

The shroud-cooling argon flow rate, temperature, and pressure are additional boundary conditions to the test. To simplify modeling the QUENCH-15 experimental setup, the bundle shroud was modeled as an adiabatic surface.

With injection starting at 7,128 s, the quench phase of the experiment is currently not modeled in the simulations discussed in Sections 4 and 5. 
Figure 1 QUENCH-15 bundle cross section and rod numbering scheme (Fig. 5 of Ref. 3).

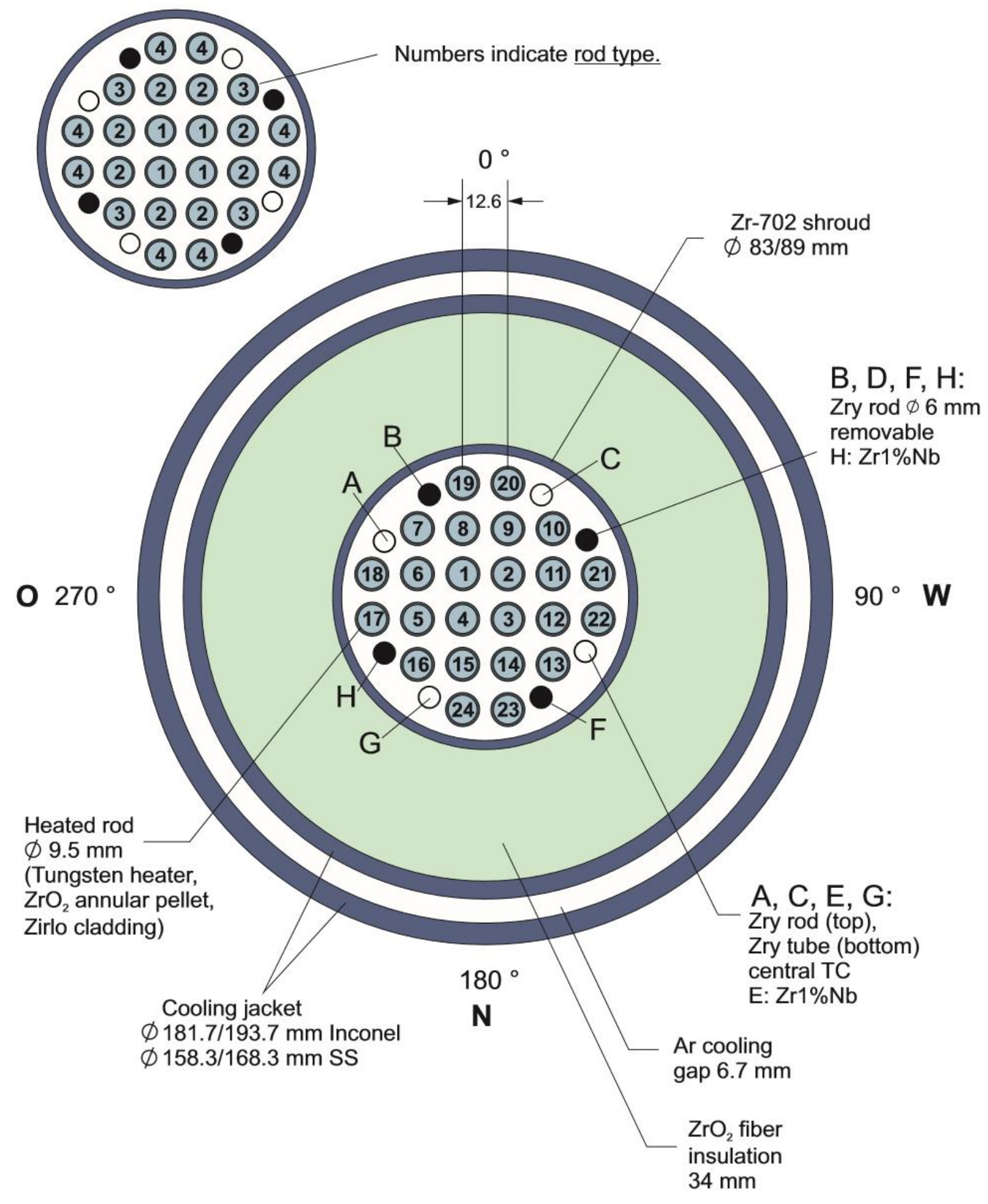

Fig.5-QUE15 Cross section.cdr 17.08.09 - IMF

Note: "Zry" indicates ZIRLO ${ }^{\mathrm{TM}}$ material 
Figure 2 QUENCH-15 test section cross section with flow lines (Fig. 4 of Ref. 3).

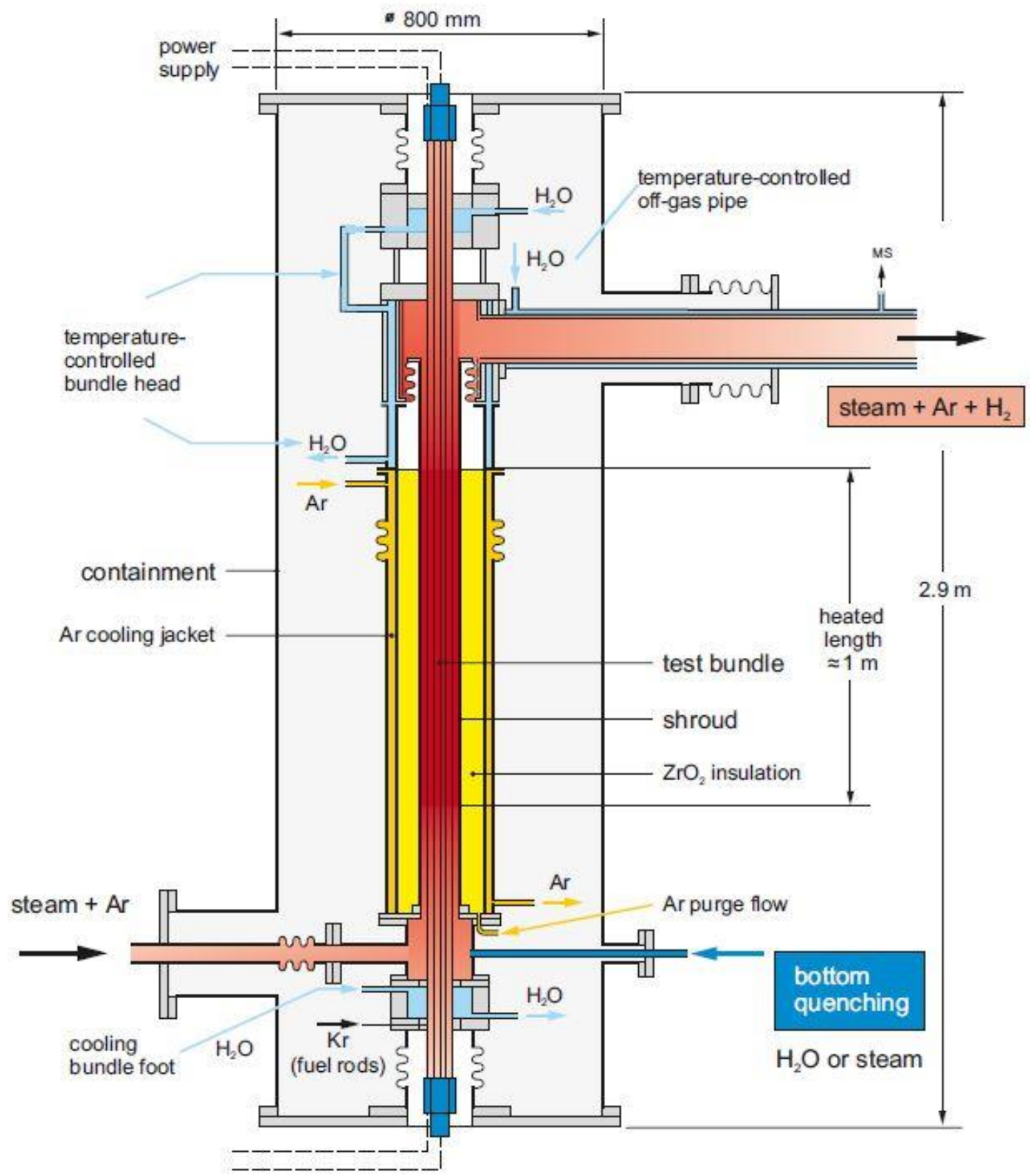

Fig 4-QUE15 Flow ines.od 05.08.09 - IMF 
Figure 3 QUENCH-15 structural axial temperature readings vs level (and simplified curves) during stabilization phase (first $134 \mathrm{~s}$ ).

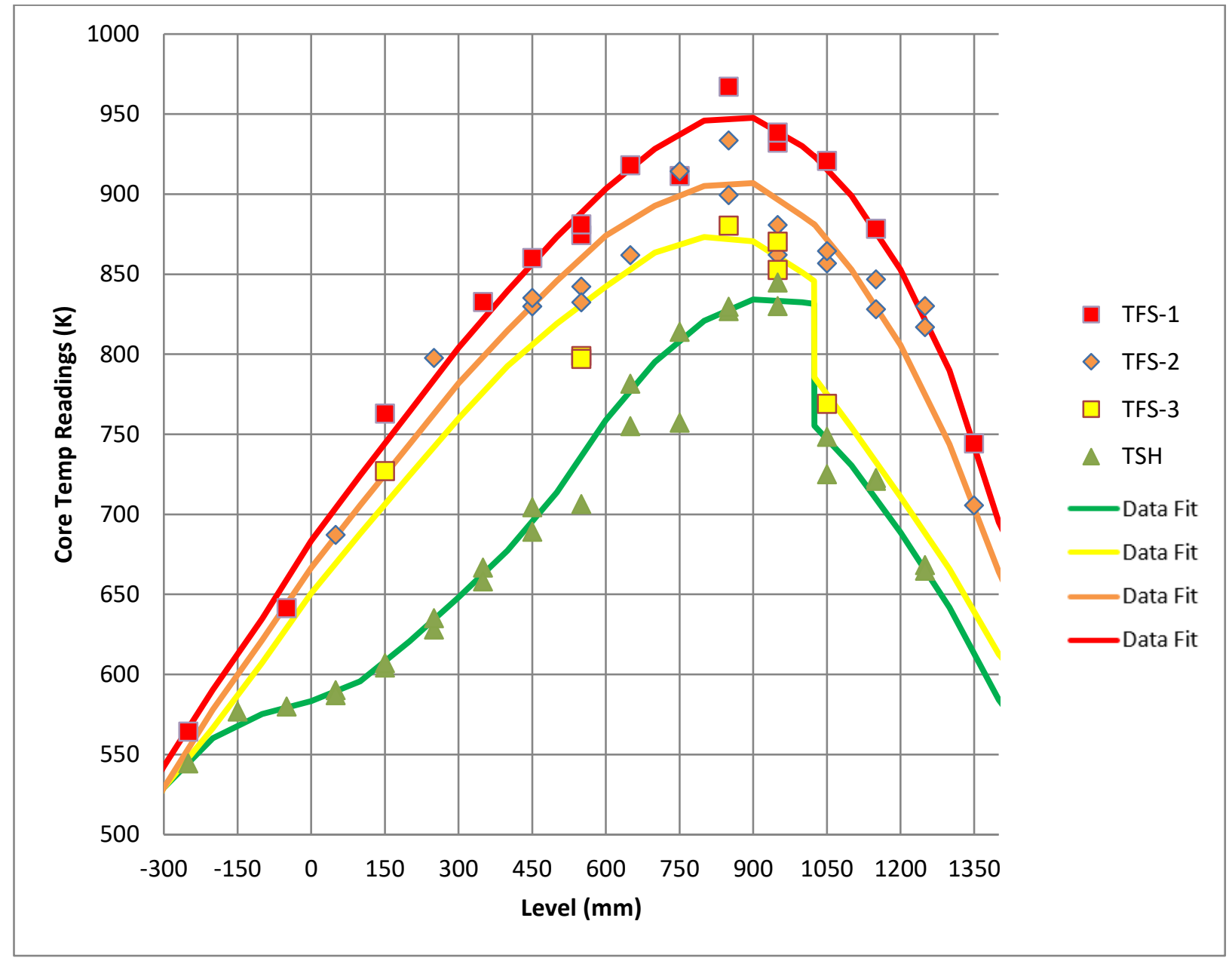


Figure 4 QUENCH-15 outer shroud (TCl) axial temperature readings vs level (and simplified curves) during stabilization phase of experiment (first $134 \mathrm{~s}$ ).

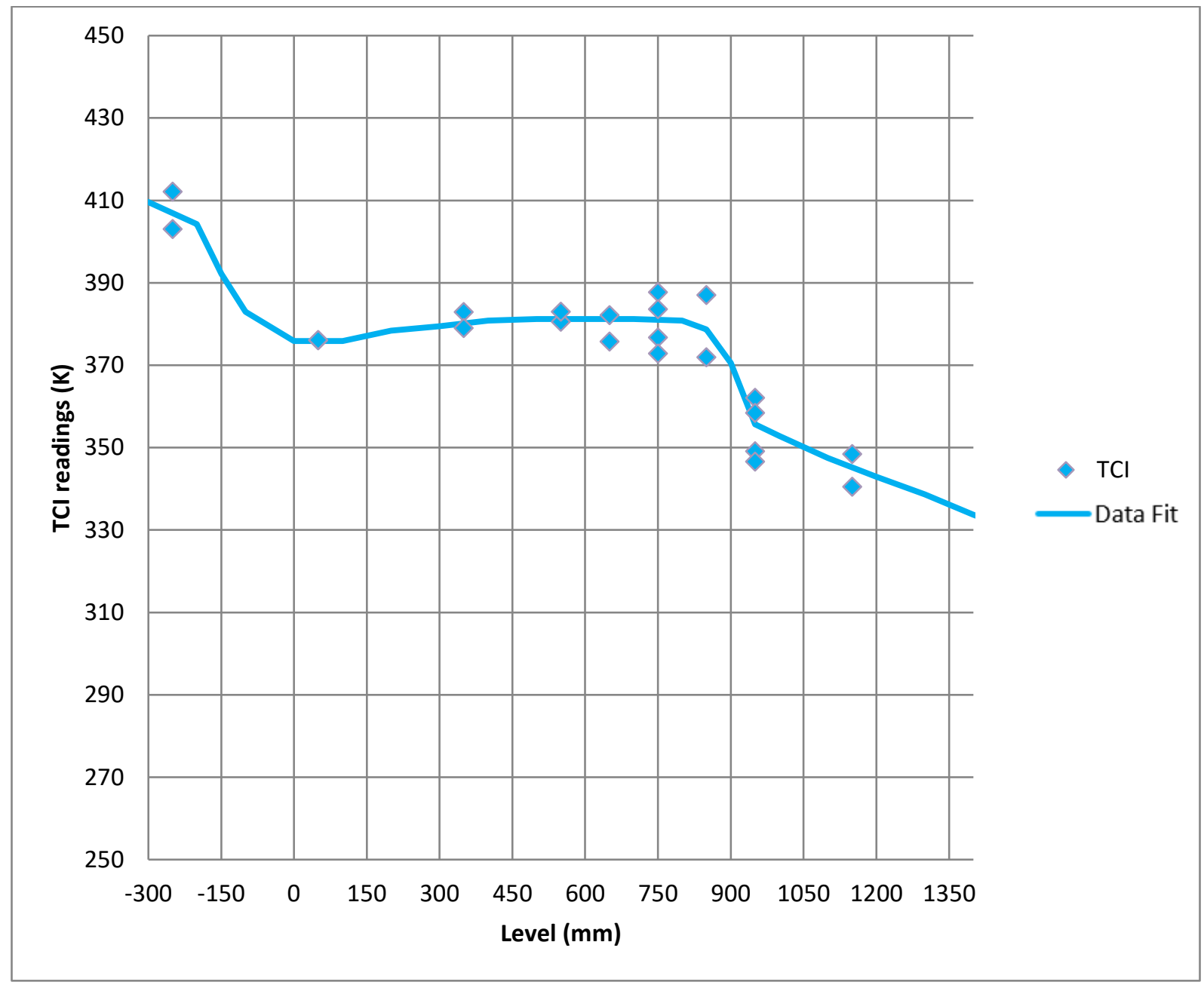


Figure 5 QUENCH-15 inlet argon flow rate (and simplified curves) throughout the experiment (FM-401).

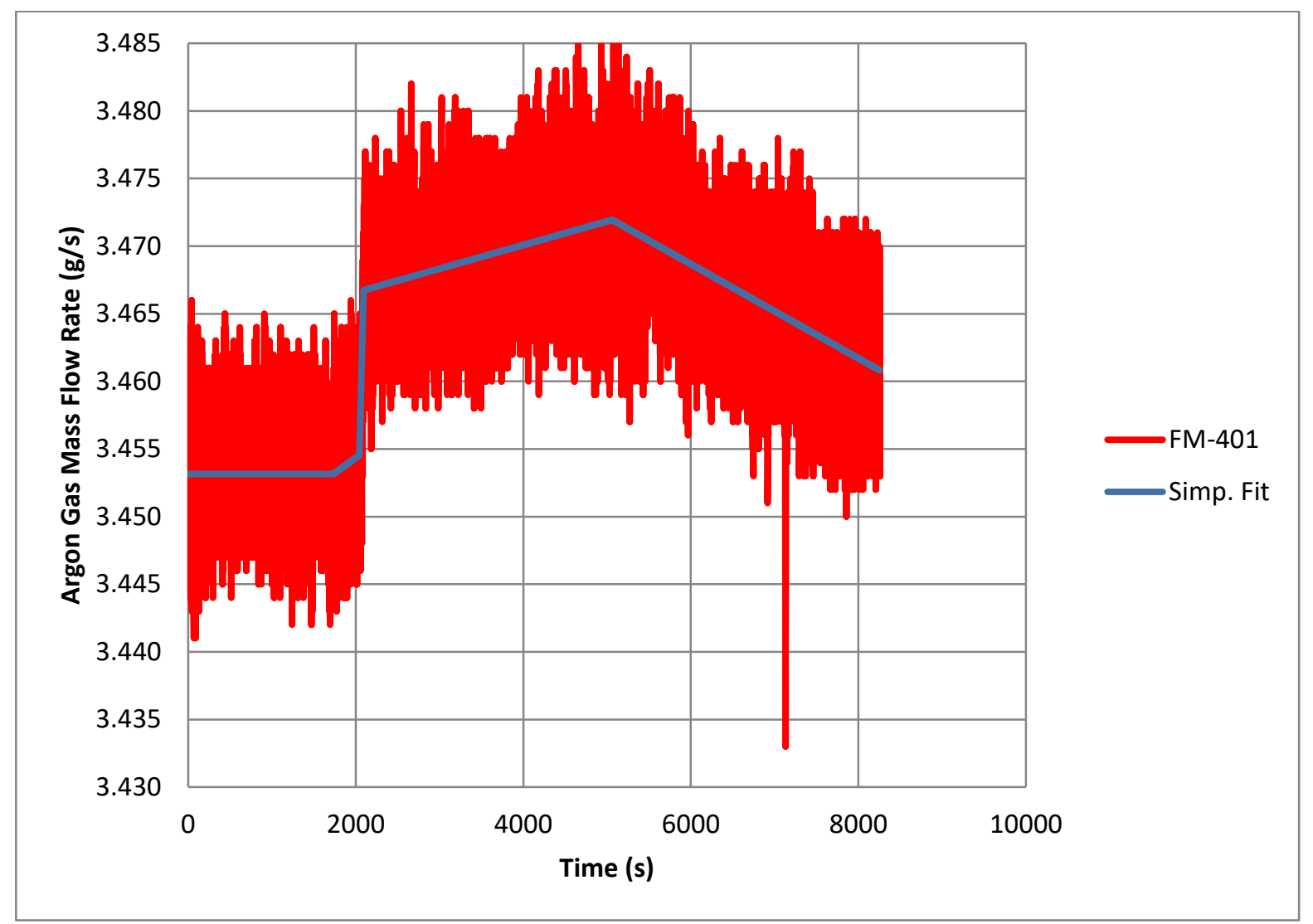


Figure 6 QUENCH-15 inlet steam flow rate (and simplified curves) throughout the experiment (FM-205).

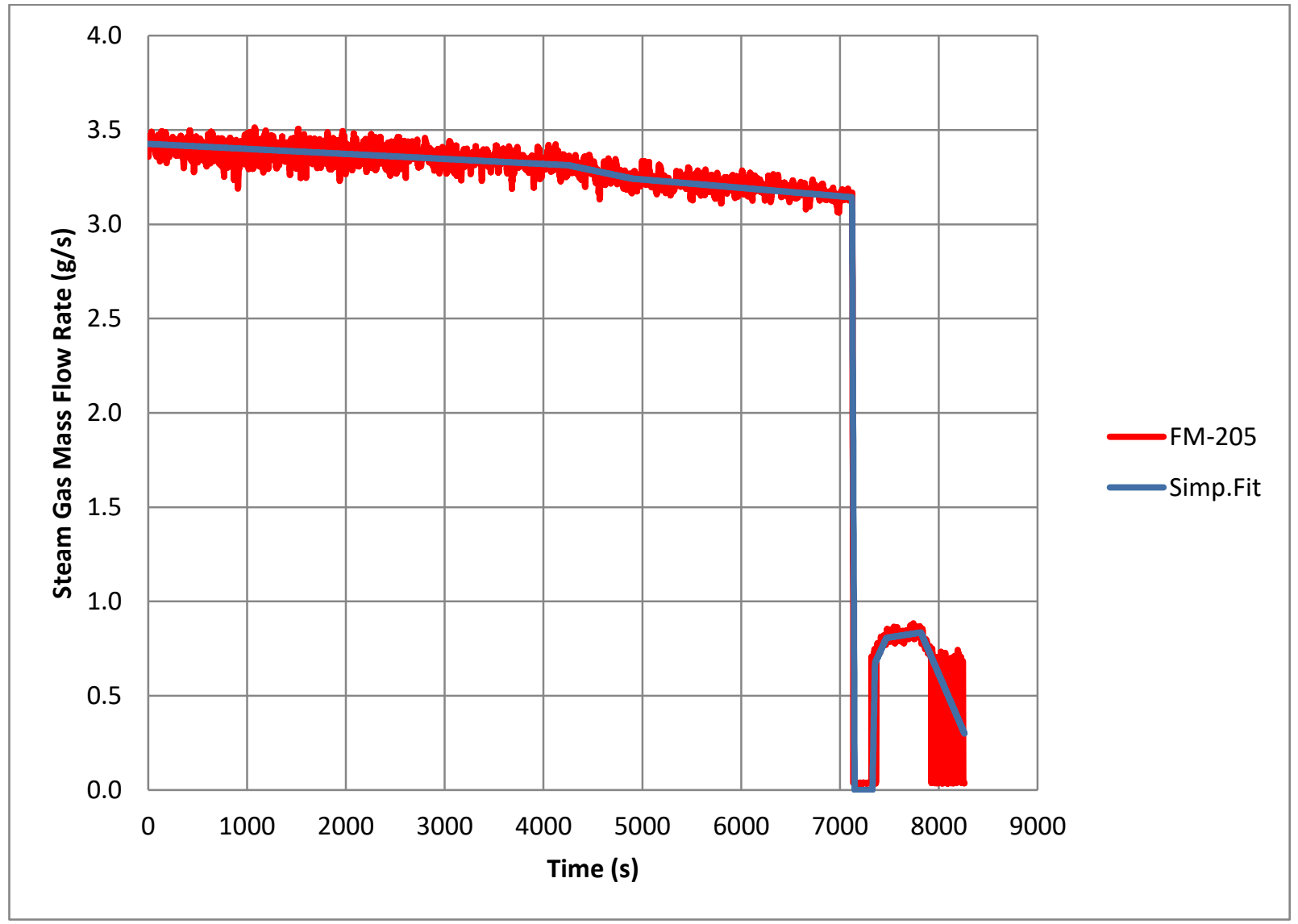


Figure 7 QUENCH-15 bundle inlet fluid temperature (and simplified curves) throughout the experiment.

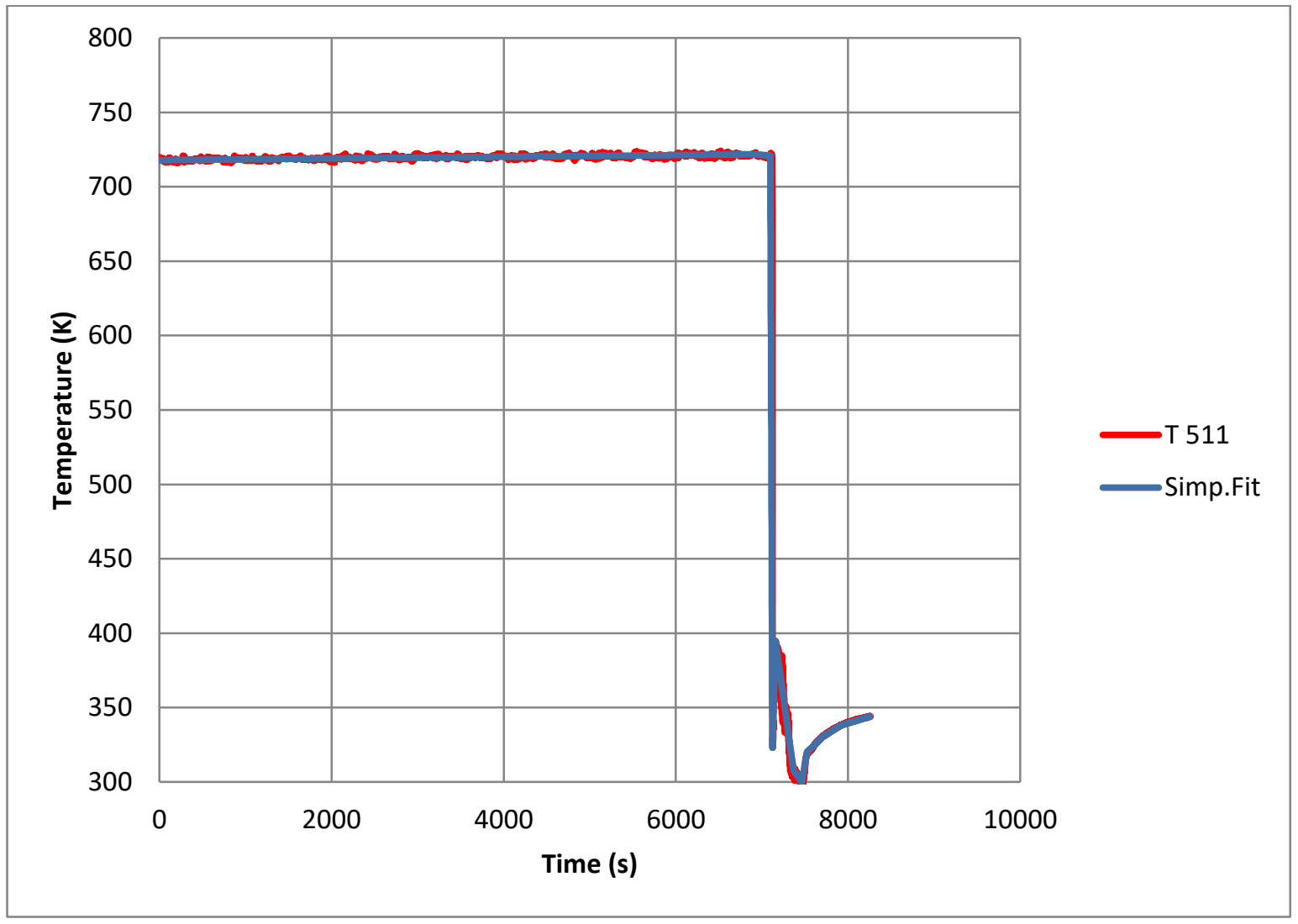


Figure 8 QUENCH-15 bundle inlet fluid pressure (and simplified curves) throughout the experiment.

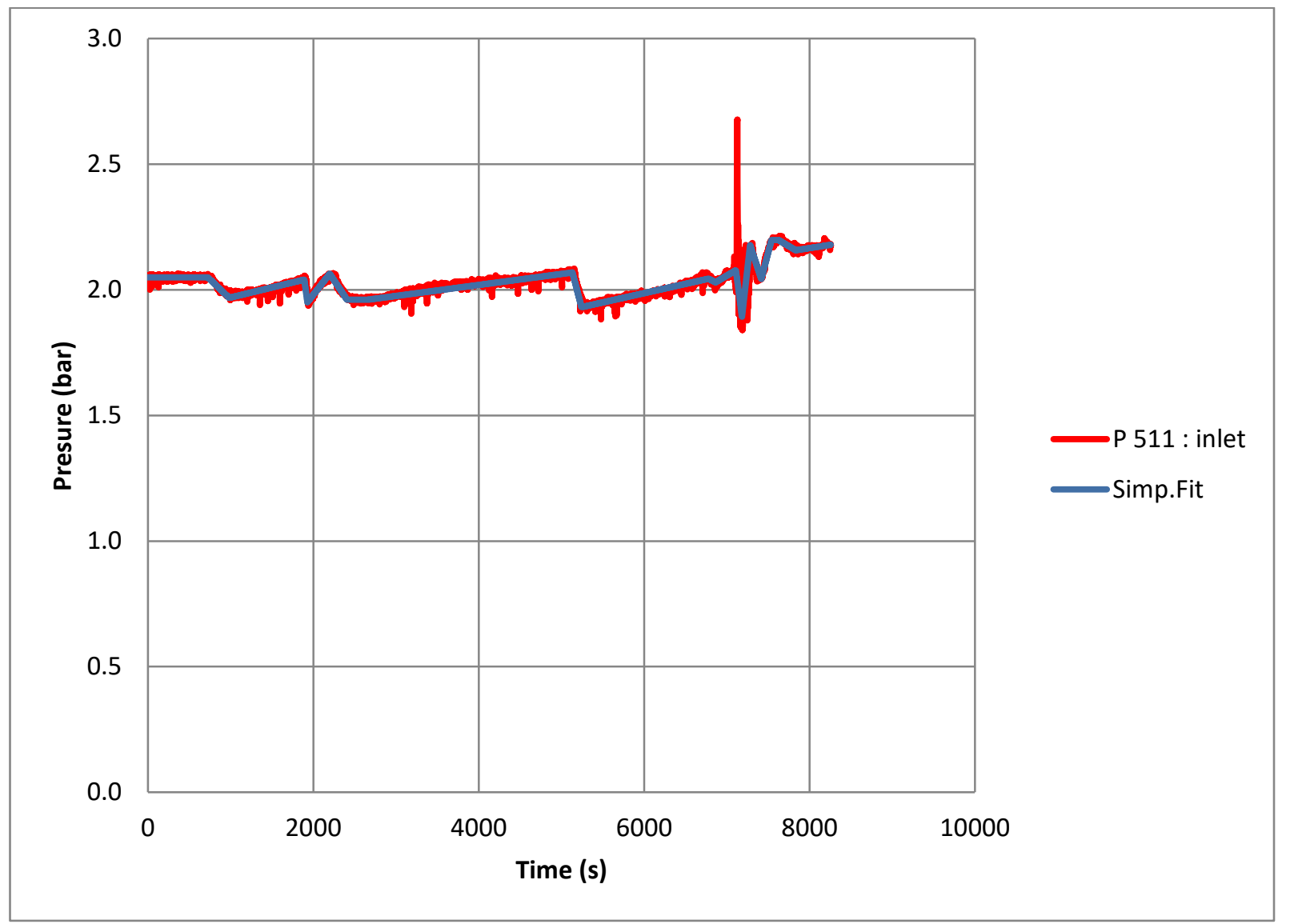


Figure 9 QUENCH-15 core gross electric power.

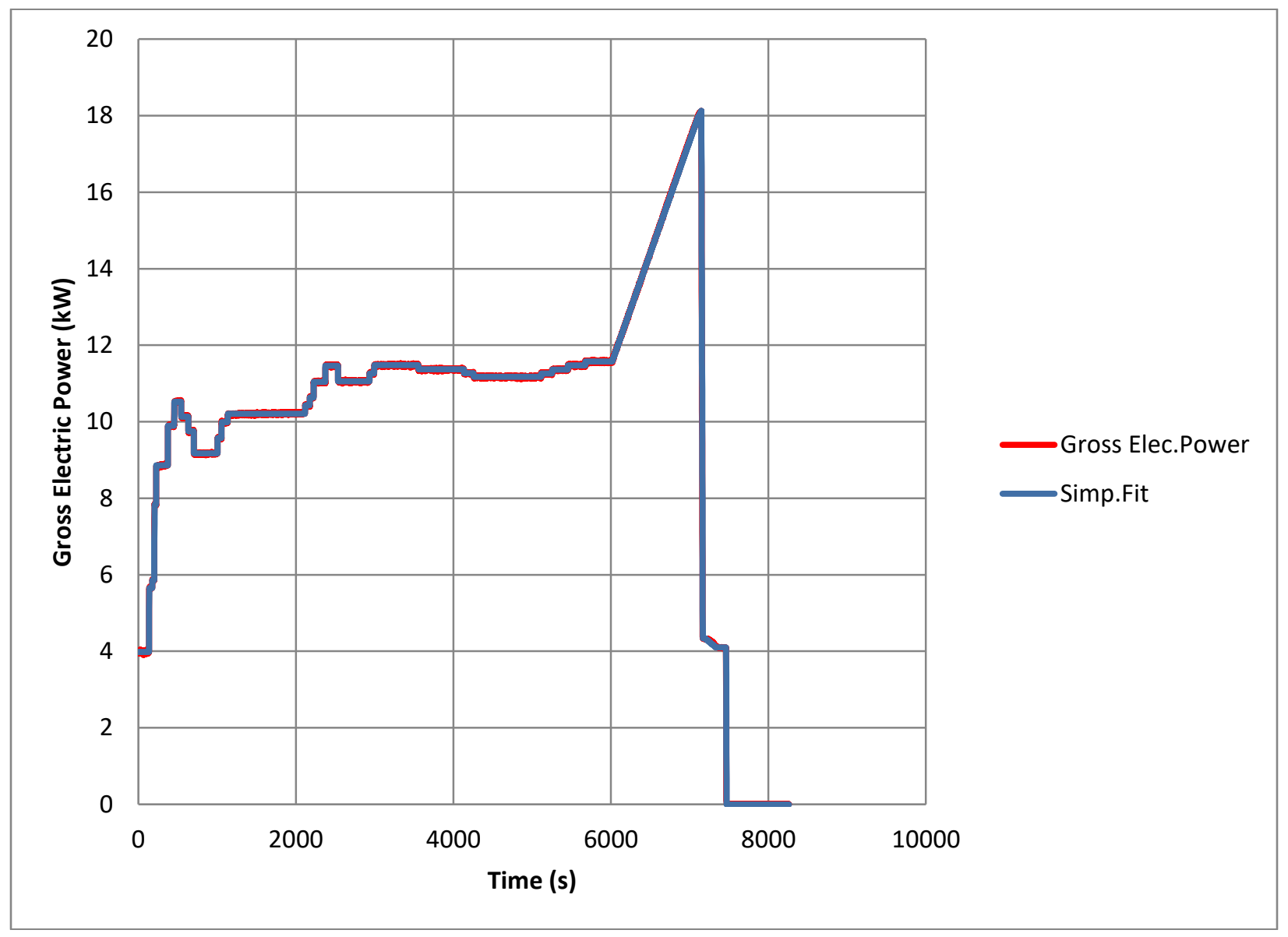




\section{OVERVIEW OF CORA and the CORA/BWR CODE}

This section provides a brief description of the CORA test series $[4,5,14]$ performed at KfK during the late 1980s and early 1990s. The CORA/BWR code [7], which was developed at ORNL in cooperation with the KfK staff for pre- and post-test analyses of the BWR experiments performed in CORA, is also described.

\subsection{CORA}

The CORA experiments were carried out in an out-of-pile facility at the KfK in Karlsruhe in the Federal Republic of Germany as part of the Severe Fuel Damage Program. This experimental program provided information on the failure mechanisms and progression of LWR fuel elements/assemblies in a temperature range from $\sim 1,475 \mathrm{~K}-2,675 \mathrm{~K}$.

Two bundle configurations were tested in CORA: pressurized water reactor (PWR) bundles and BWR bundles. Because ORNL was the national laboratory funded by the US Nuclear Regulatory Commission (NRC) for the study of severe accidents in BWRs, ORNL became involved in this experimental program when planning for CORA BWR tests was initiated In the CORA BWR test section configuration (see Figure 11), the fuel rods (electrically heated and unheated rods) were surrounded by a Zircaloy shroud with the absorber blade (B4C-filled tubelets with a stainless steel sheath containment) in the middle of the test section, with half of the fuel rods on both sides of the blade. A Zircaloy wall on both sides of the blade represented the BWR fuel assembly's Zircaloy channel box wall. The test bundles were subjected to temperature transients of a slow heat-up rate in a steam and argon environment. Test conditions were guided in general by severe accident studies of possible accident scenarios in commercial reactors.

The transient phases of the CORA tests were initiated with a temperature ramp rate of $\sim 1 \mathrm{~K} / \mathrm{s}$. The temperature escalated due to the exothermic Zircaloy/steam reaction starting at $\sim 1,375 \mathrm{~K}$ which led to bundle maximum temperatures of $\sim 2,275 \mathrm{~K}$ or greater. At these temperatures, significant bundle liquefaction/relocation started in the upper axial region of the test bundles. In the BWR test series, this structural "melting" started with the absorber/steel reaction/liquefaction at about $1525 \mathrm{~K}$. This melt then relocated downward within the test section, attacking the channel box wall, and after failure of the wall, it flooded into the fuel assembly and attacked the fuel rod cladding (and fuel). Extensive blockage of the lower axial portion of these test sections occurred because the liquified core components relocated downward, freezing in the cooler, lower portion of the core.

A schematic of the CORA test facility is shown in Figure 12. Note that in Figure 12, the water-filled quench tank is below the test bundle. In an experiment involving quench of the core, the quench tank would be hydraulically raised, enveloping the test bundle and the bundle shroud. In the QUENCH experiments, the quenching water is injected into the lower plenum of the test section (see Figure 2) and rises within the fuel assembly within the test bundle Zircaloy liner of the shroud.

As shown in Figure 13, the test assembly (Figure 11) is radially surrounded by a high-temperature insulated shield. Most test configuration contained cut-outs in the test assembly shroud and the high temperature shield so that videos be could made of the interior of the fuel assembly during the test. Twocolor pyrometer temperature measurements could also be made through the videoscopes and the shroud cut-outs.

These CORA test assemblies were extensively instrumented, and instruments were also included outside the test sections. Extensive post-mortem examinations of the test assemblies were also conducted. These tests allowed for investigation of the relevant core damage mechanisms in an uncovered core with 
increasing temperatures. The data allowed the development of models for estimating core damage initiation and propagation.

\subsection{The CORA/BWR CODE}

The CORA/BWR code [7] was designed to predict the heat transfer rates, steaming rates, fluid flow, chemical reaction rates, and temperatures in the experimental test section during BWR experiments in the CORA facility. The heat transfer processes include conduction in solid structures, convection and boiling in the liquid phase, convection and radiation in the gas phase, and radiation between the interacting structural surfaces. Solid structures (fuel rod, channel wall, control blade, shrouds, etc) are discretized radially, axially, and azimuthally forming a simplified 3D representation. The transient thermal equations, these are solved implicitly and account for conduction, convection, thermal radiation, as well as chemical and electrical energy input. The fluid region is divided into six subchannels surrounding the fuel pins and an interstitial region for the periphery. Mass and energy equations are solved for the subchannels. However, the momentum equation is not solved and there is no intermixing of fluid between subchannels. Metal/steam reaction kinetics are modeled to determine the reaction rates of steam with metal structures in the rods, canister, and liner and the control blade and with the B4C absorber in the control blade. From the metal/steam reaction, calculations are derived for the hydrogen generation rate and the temporal and spatial distribution of oxide formations. The code also has models for component interactions leading to melting/liquefaction, subsequent melt relocation/freezing/re-melting, and interaction of the melts with intact geometries as the melts relocate. The code is thus able to provide estimates of the temperature history of the test assembly, as well as clad oxidation, hydrogen generation, and the extent of liquefaction (melting) and relocation of assembly components.

For the BWR experiments [14], CORA/BWR models a quarter cross section of the shroud and fuel assembly (see Figure 13). Radially, the model includes the high temperature shroud, and axially, it includes the quench tank below the core. It is essentially a three-dimensional model of the test assembly, high temperature shroud (from the test section inlet through to the test section outlet), and the quench tank (which cools the lower portion of the core electrically heated fuel rods).

The CORA/BWR code was exercised extensively in the pre- and post-test analyses $[8,9,10,11,12$, 13] of all the BWR experiments (see Table 1) performed in the CORA test facility.

Table 1 CORA BWR test matrix.

\begin{tabular}{ccclc}
\hline $\begin{array}{c}\text { Test } \\
\text { No. }\end{array}$ & $\begin{array}{c}\text { Max. cladding } \\
\text { temperature }\end{array}$ & $\begin{array}{c}\text { Absorber } \\
\text { material }\end{array}$ & \multicolumn{1}{c}{ Other test conditions } & Date of test \\
16 & $\sim 2,275 \mathrm{~K}$ & B4C & BWR absorber & 24 Nov 1988 \\
17 & $\sim 2,275 \mathrm{~K}$ & B4C & BWR absorber with quenching & 29 June 1989 \\
18 & $<2,275 \mathrm{~K}$ & B4C & 59-rod bundle with slow cooling & 21 June 1990 \\
31 & $\sim 2,275 \mathrm{~K}$ & B4C & Slow initial heatup $(\sim 0.3 \mathrm{~K} / \mathrm{s})$ & $25 \mathrm{June} 1991$ \\
28 & $\sim 2,275 \mathrm{~K}$ & $\mathrm{~B} 4 \mathrm{C}$ & Pre-oxidized & $25 \mathrm{Feb} 1992$ \\
33 & $\sim 2,275 \mathrm{~K}$ & B4C & Dry core conditions, no extra steam input & 1 Oct 1992
\end{tabular}

The post-test analyses [12] of the CORA 33 test was published in late 1993; at that time, it was essentially mothballed until late 2017, when it was resurrected for computational support for the QUENCH-19 test. Twenty-four years after the code's last execution, the CORA/BWR Fortran code was compiled with a new compiler and executed with a very new computing platform using the CORA-31 input file from 1991. Figure 14 illustrates the results compared against CORA-31 data, which are the same as the results published in the post-test analyses documentation for the CORA-31 test [11]. This simulation of CORA-31 confirmed that the code still performs correctly using the new compiler and computing system. 
Figure 10 BWR fuel assembly configuration and the representative CORA test bundle configuration.

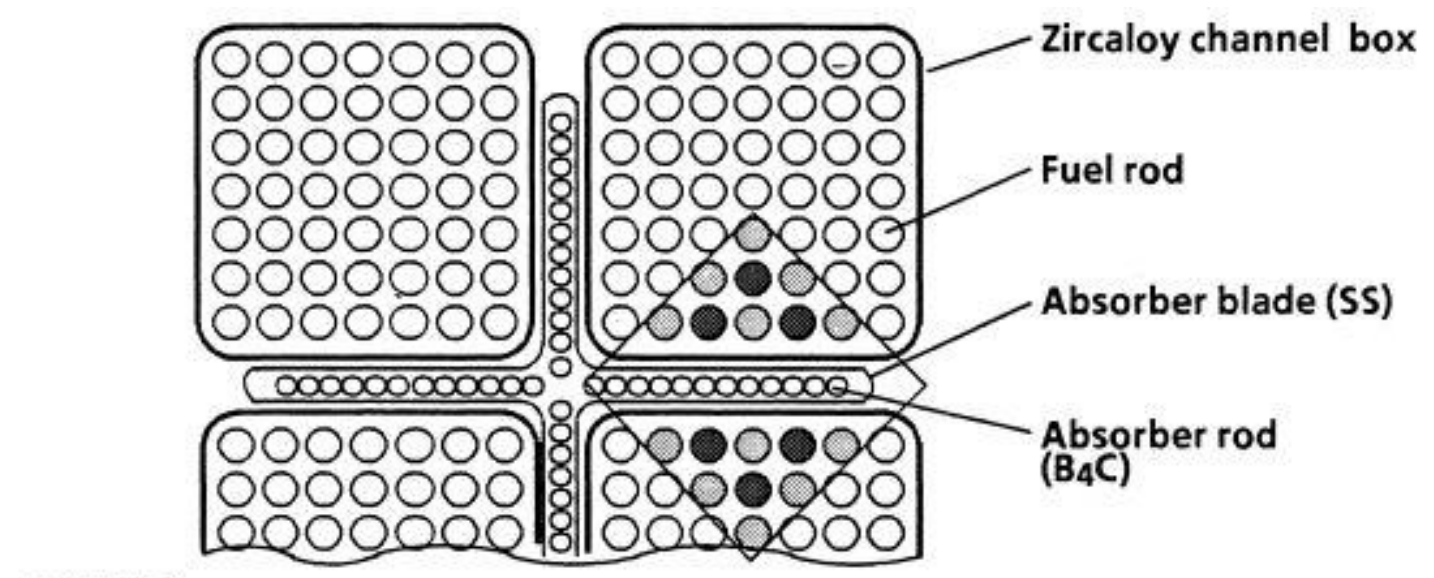

\section{BWR}

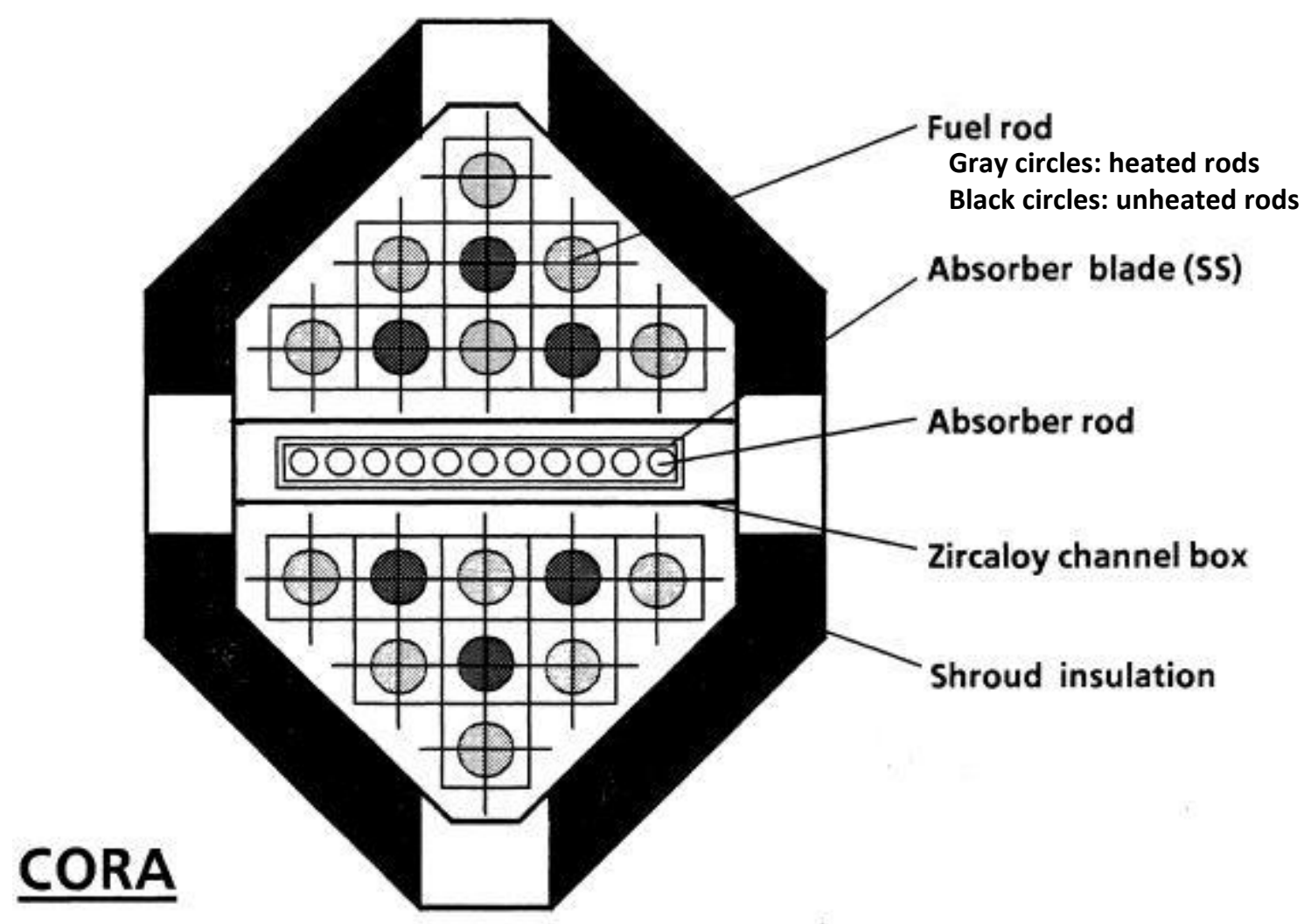


Figure 11 Main components of the KfK CORA test facility.

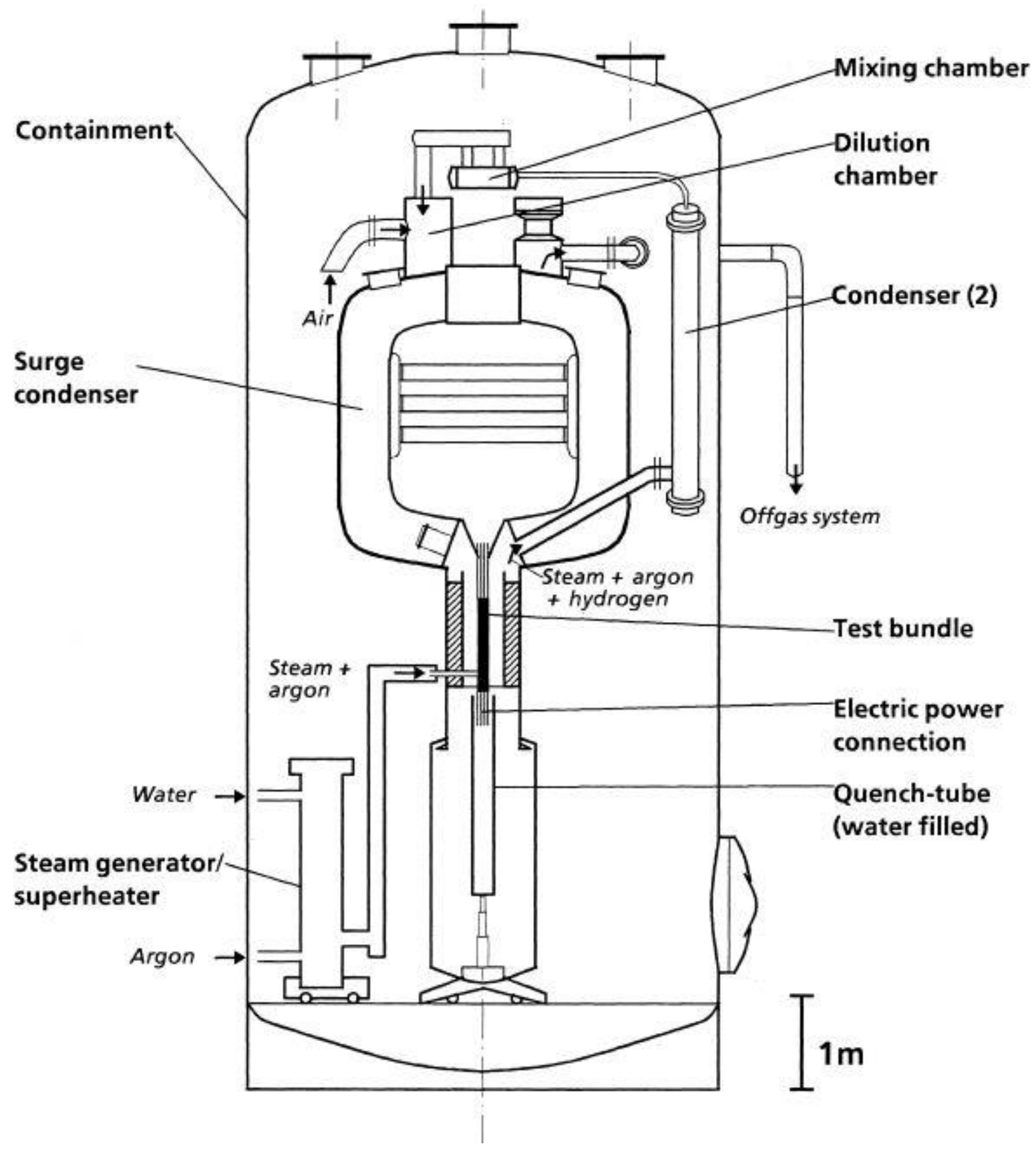


Figure 12 General axial/radial configuration of the CORA test section.

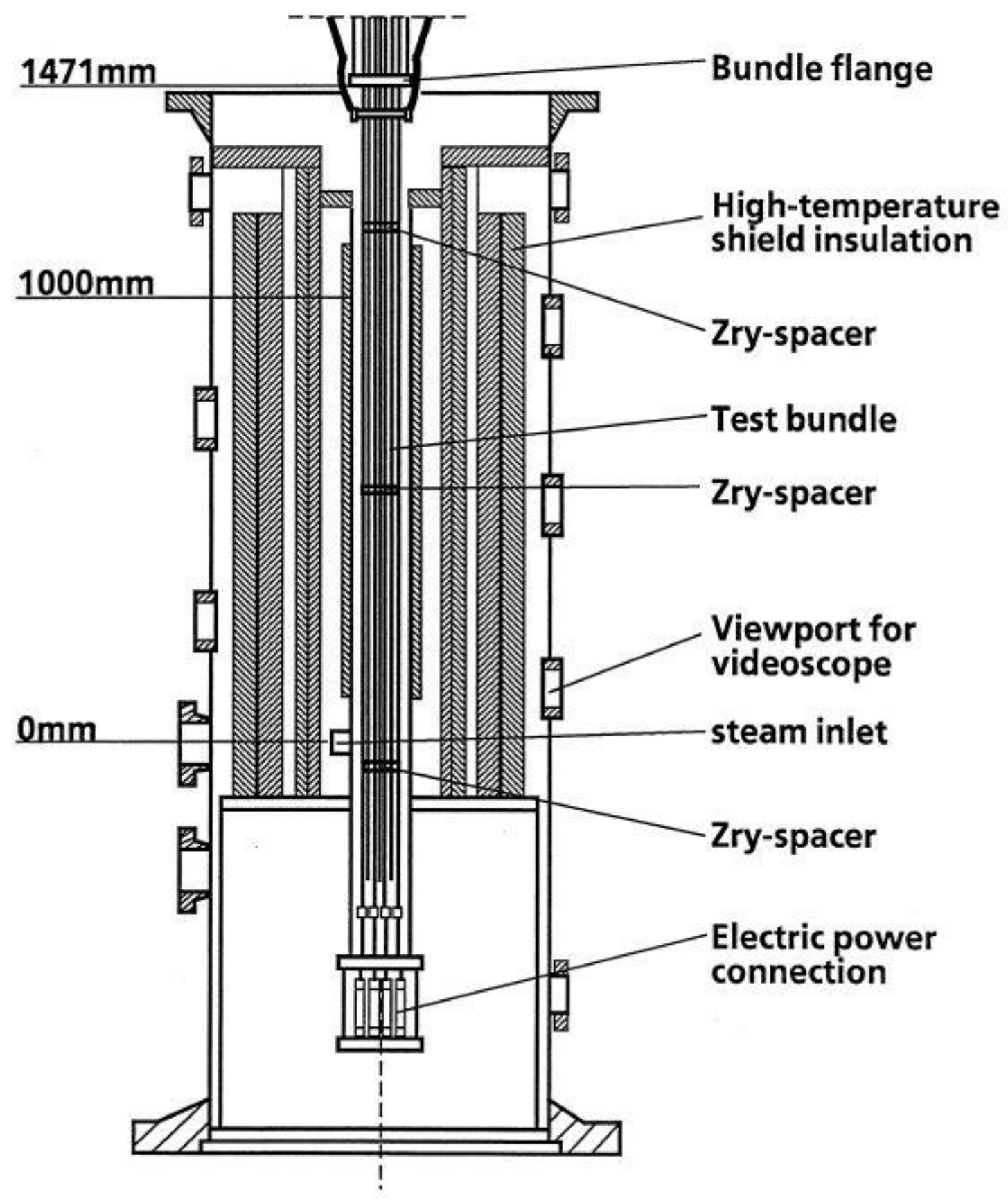


Figure 13 Quarter section of BWR test section modeled by the CORA/BWR code

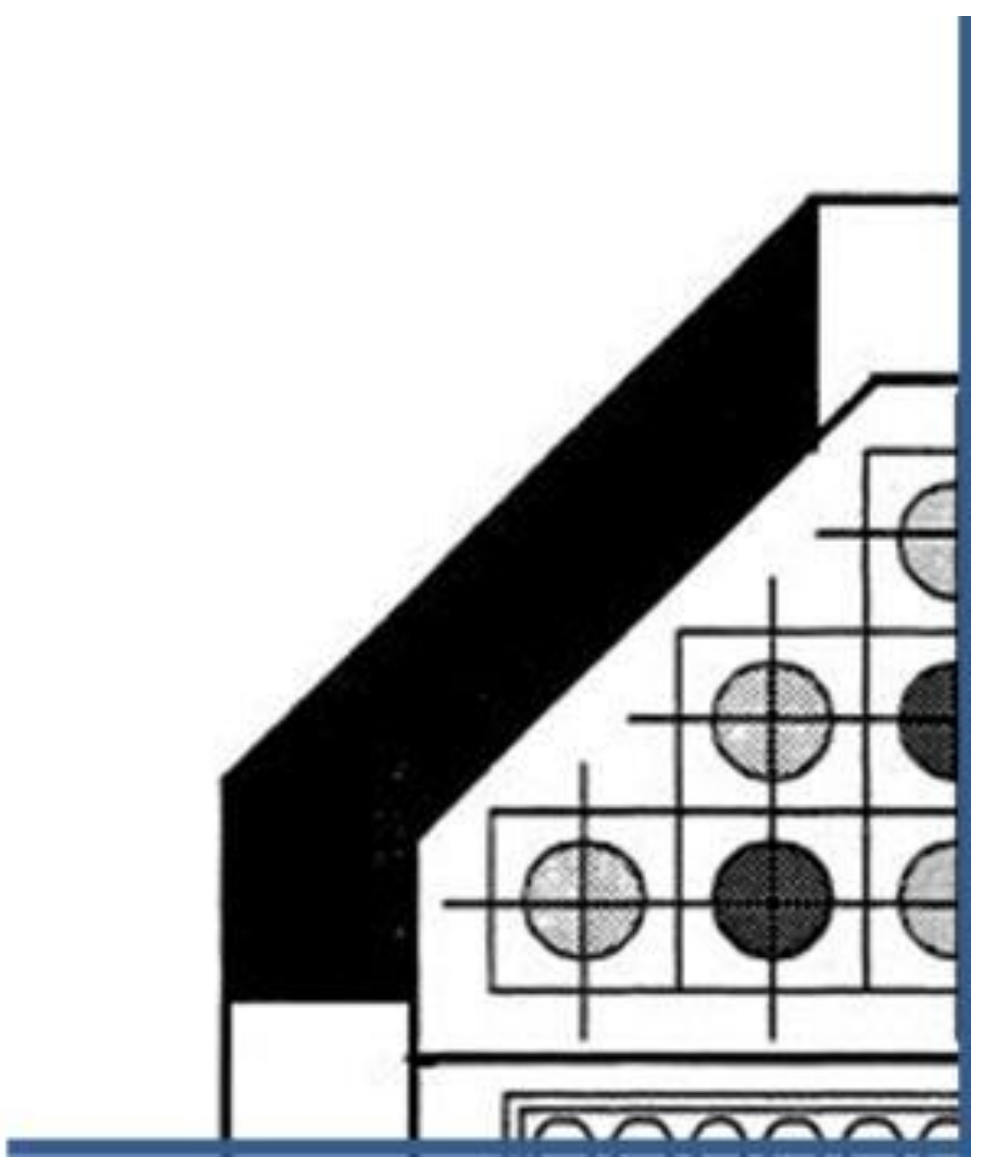


Figure 14 CORA/BWR simulation of the CORA-31 test.
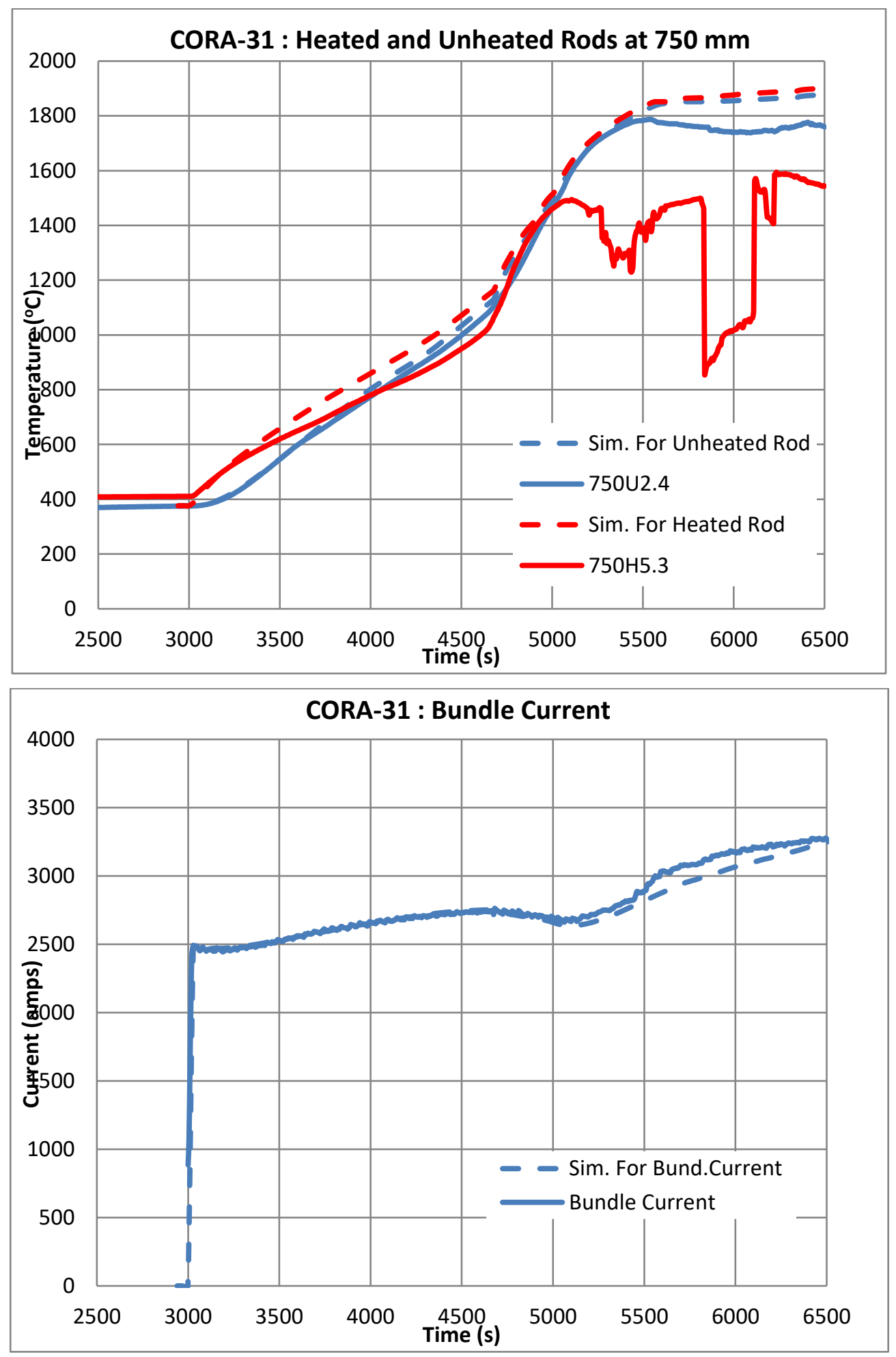


\section{MODELING QUENCH TESTS AND QUENCH-15 ANALYSIS}

Even though it was confirmed that the CORA/BWR code is operational (Section 3.2), the geometries to be modeled (see Figure 1 and Figure 10) are very different. In addition, there is no quench tank in the QUENCH facility, and the shroud(s) surrounding the test sections are different. Since the CORA/BWR code was designed to specifically model the CORA BWR test configuration and facilities, significant and essential codes changes were required to model the QUENCH test section. These code modifications included changing the hardcoded structures to reflect the geometry and materials of the QUENCH facility. The interstitial area around the bundle is different and does not include a BWR control blade or holes through the shroud. Finally, the quench tank used in the CORA facility was disabled in the code.

After the code modifications, another confirmation step was required to validate the code's usage for analyzing the QUENCH experiments. It was decided to first simulate the QUENCH-15 experiment since the desire for QUENCH-19 is to replicate the QUENCH-15 test (except using FeCrAl core components). The initial and boundary conditions employed for the simulation of QUENCH-15 and 19 are given in Section 2.3

The code (now designated as CORA/BWR-QUENCH) executed successfully through the test phases up to the quench phase. The code subroutines to model flooding of the bundle are associated with the CORA quench tank subroutines which have been deactivated in the CORA/BWR-QUENCH code. The code will require additional modifications to model the quench phase.

The simulation results for QUENCH-15 are presented in Figure 15 through Figure 18. The solid lines indicate data from the QUENCH-15 test, [3], and the dashed lines are the predictions by CORA/BWRQUENCH. For the temperature plots (Figure 20 through Figure 23), the green curves present the metal shroud (TSH) temperature while the other colors are used for the fuel rod simulators (TFS).

The temperature plots (Figure 15 through Figure 17) very successfully replicate the QUENCH-15 data. The simulation closely matches the peak rod temperatures (Figure 17) at the $950 \mathrm{~mm}$ level of approximately $1,900 \mathrm{~K}$. Also, the predicted hydrogen generation (Figure 18) data are in good agreement with the experiment data.

These simulation results confirm the applicability of the CORA/BWR-QUENCH code for modeling the QUENCH test facility and tests. 
Figure 15 CORA/BWR-QUENCH simulation results for the 450 and $650 \mathrm{~mm}$ levels.
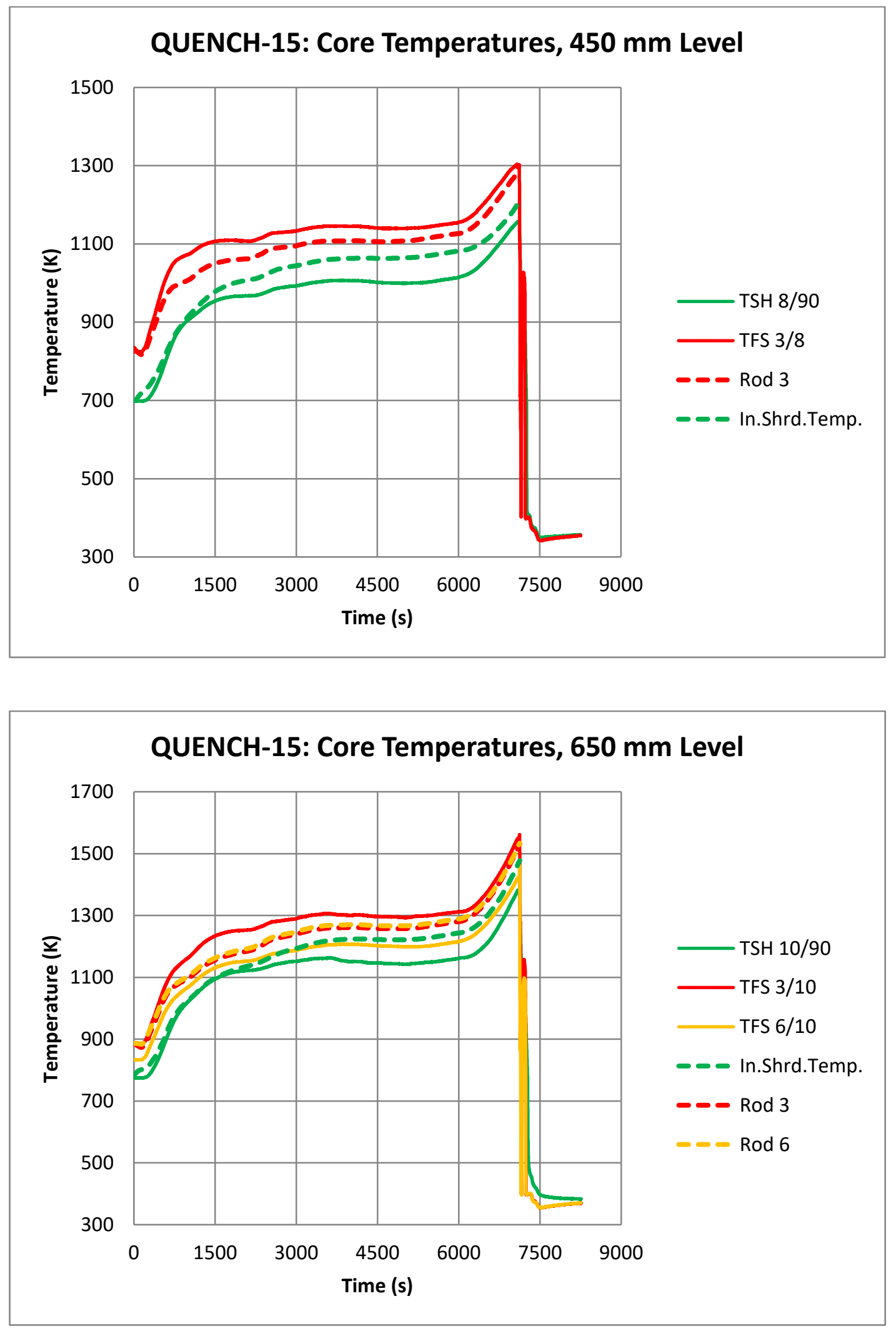
Figure 16 CORA/BWR-QUENCH simulation results for the 750 and $850 \mathrm{~mm}$ levels.
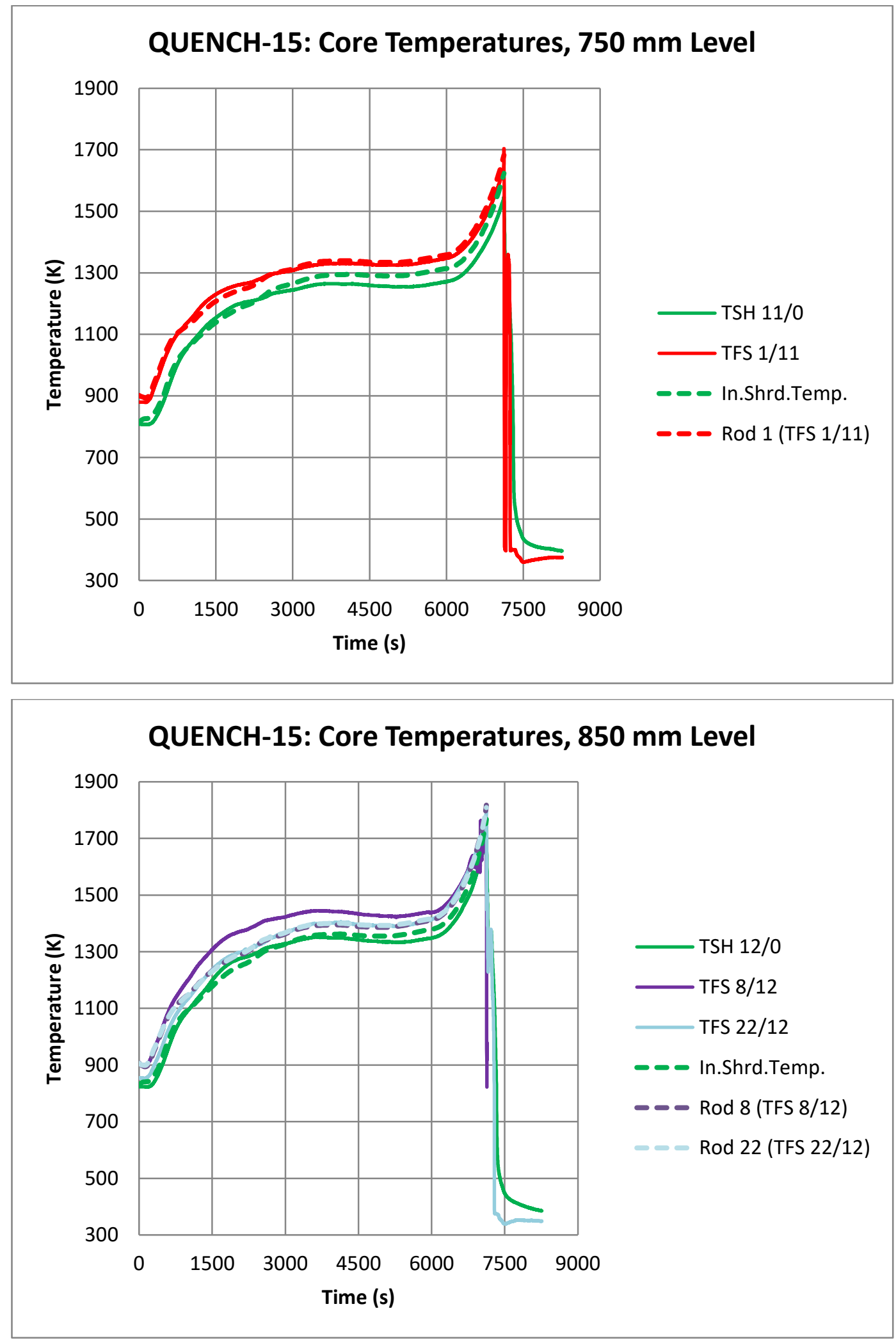
Figure 17 CORA/BWR-QUENCH simulation results for the $950 \mathrm{~mm}$ level.

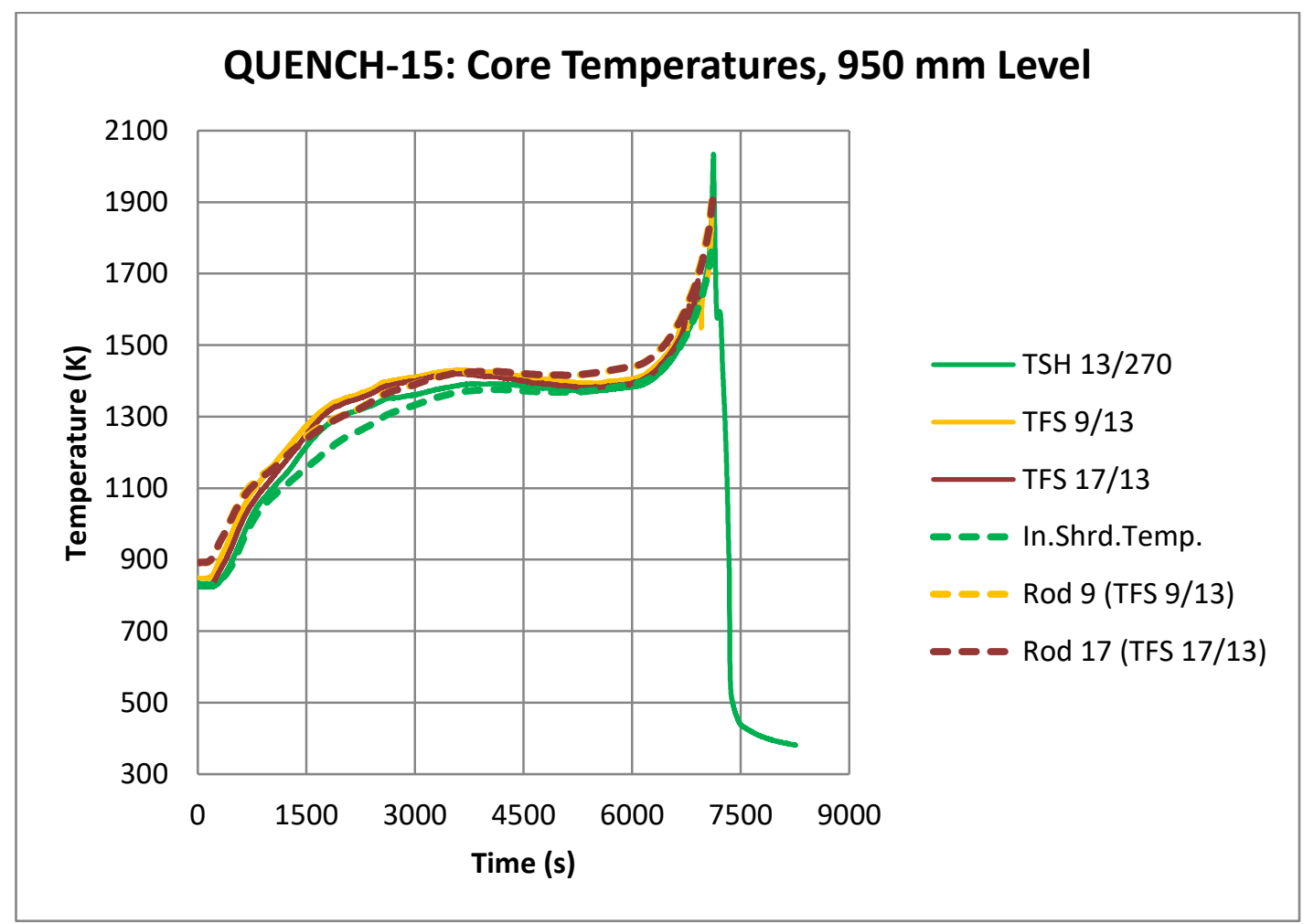

Figure 18 CORA/BWR-QUENCH simulation results for the integrated hydrogen core outlet flow.

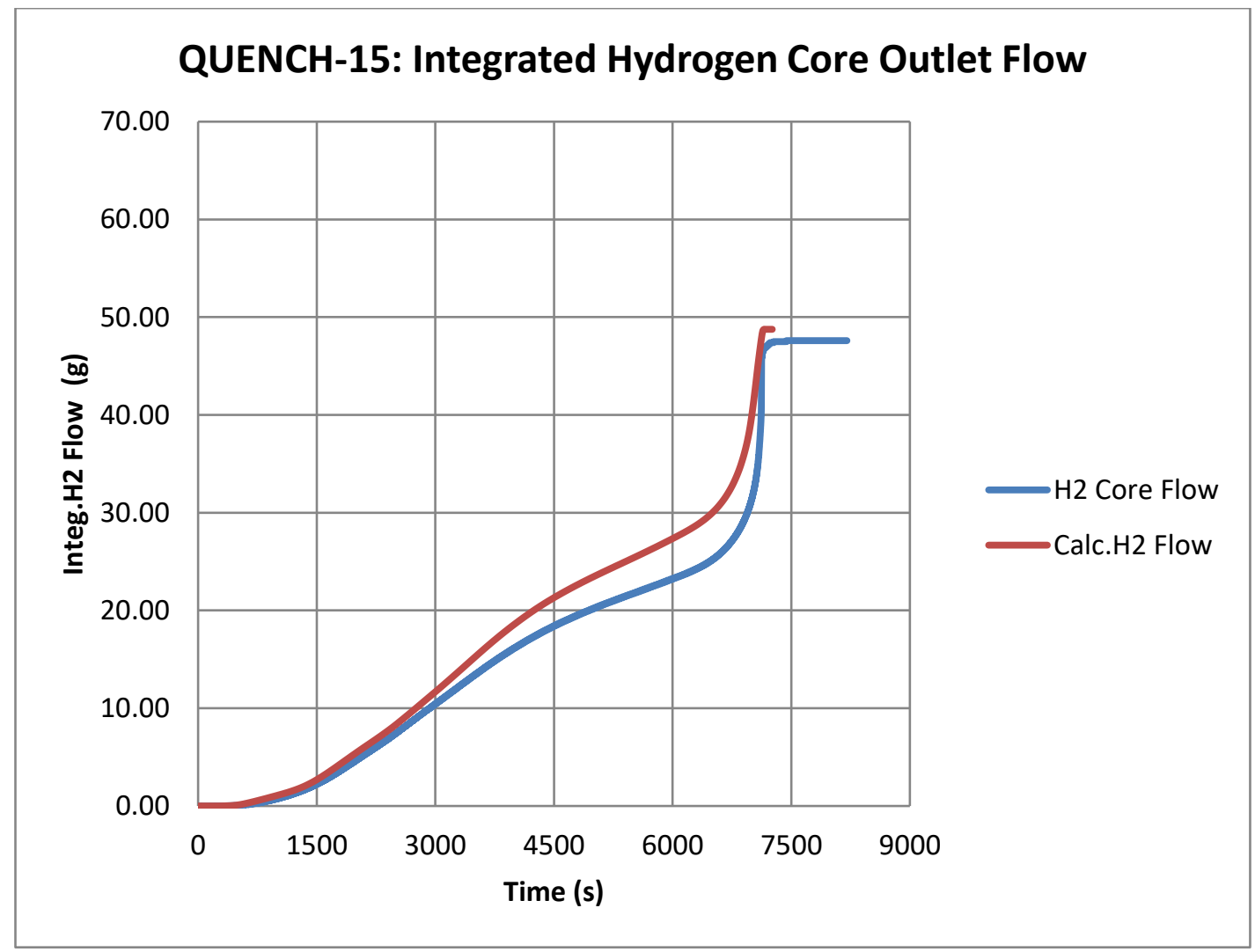




\section{QUENCH-19 SIMULATION RESULTS}

To model QUENCH-19, the metal reaction kinetics was the only item modified in the CORA/BWRQUENCH code or the code input (i.e., the QUENCH-15 input file). The oxidation kinetics item for Zircaloy was scaled by a factor of 250 based on the kinetics comparison that has been extensively employed in ORNL past presentations [15] (Figure 19). This is representative of the much lower oxidation kinetics of FeCrAl. The heat of the reaction was also scaled by a factor of 3 reduction. Future work includes implementing the oxidation kinetics that were developed for the specific FeCrAl alloy (B136Y) to be used in QUENCH-19 [6].

Since it is the intent to replicate the initial and boundary conditions of the QUENCH-15 test in the conduct of the QUENCH-19 experiment, all model inputs are identical. The initial and boundary conditions employed for the code simulation are given in Section 2.3, and they are the same as employed in Section 4.

As with the QUENCH-15 simulation, CORA/BWR-QUENCH executed successfully through the test phases up to the quench phase. The code will require additional modifications to model the quench phase.

The simulation results are presented in Figure 20 through Figure 24. As with Section 4, the solid line indicates data from the QUENCH-15 test and the dashed lines are the predictions by CORA/BWRQUENCH for the QUENCH-15 test. The dotted lines are the predictions by the CORA/BWR-QUENCH code for the QUENCH-19 test (with FeCrAl). In the temperature plots (Figure 20 through Figure 23), the green curves present the metal shroud (TSH) temperature while the other colors are used for the fuel rod simulators (TFS).

At levels below mid-core (Figure 20), the $\mathrm{Zr}$ (dashed lines) and the FeCrAl curves (dotted lines) are nearly the same because the clad temperatures have not exceeded 1,273 K (the $\mathrm{Zr} /$ steam reaction is minor), and the temperature increase is being driven solely by the electrical power input. However, from $650-950 \mathrm{~mm}$, the deviation between the $\mathrm{Zr}$ and $\mathrm{FeCrAl}$ predictions steadily increase due to the higher metal/steam reaction of the Zircaloy. At the peak temperature position $(950 \mathrm{~mm}$, Figure 22 and Figure 23 ), the peak $\mathrm{FeCrAl}$ temperature is nearly $300 \mathrm{~K}$ lower than the $\mathrm{Zr}$-clad fuel rods. The predicted peak temperature of the $\mathrm{FeCrAl}$ clad fuel rod at the $950 \mathrm{~mm}$ level is $\sim 1620 \mathrm{~K}\left(\sim 1,347^{\circ} \mathrm{C}\right)$.

The predicted hydrogen generation (Figure 24) is significantly lower for the $\mathrm{FeCrAl}$ clad QUENCH-19 at $\sim 1.7 \mathrm{~g}$ than the QUENCH-15 Zr clad core at $\sim 48.8 \mathrm{~g}$. This was anticipated due to the slower oxidation kinetics and lower temperatures experienced by the $\mathrm{FeCrAl}$ cladding. 
Figure 19 Comparison of advanced Fe-based alloys' steam oxidation rate with Zr alloys [15].

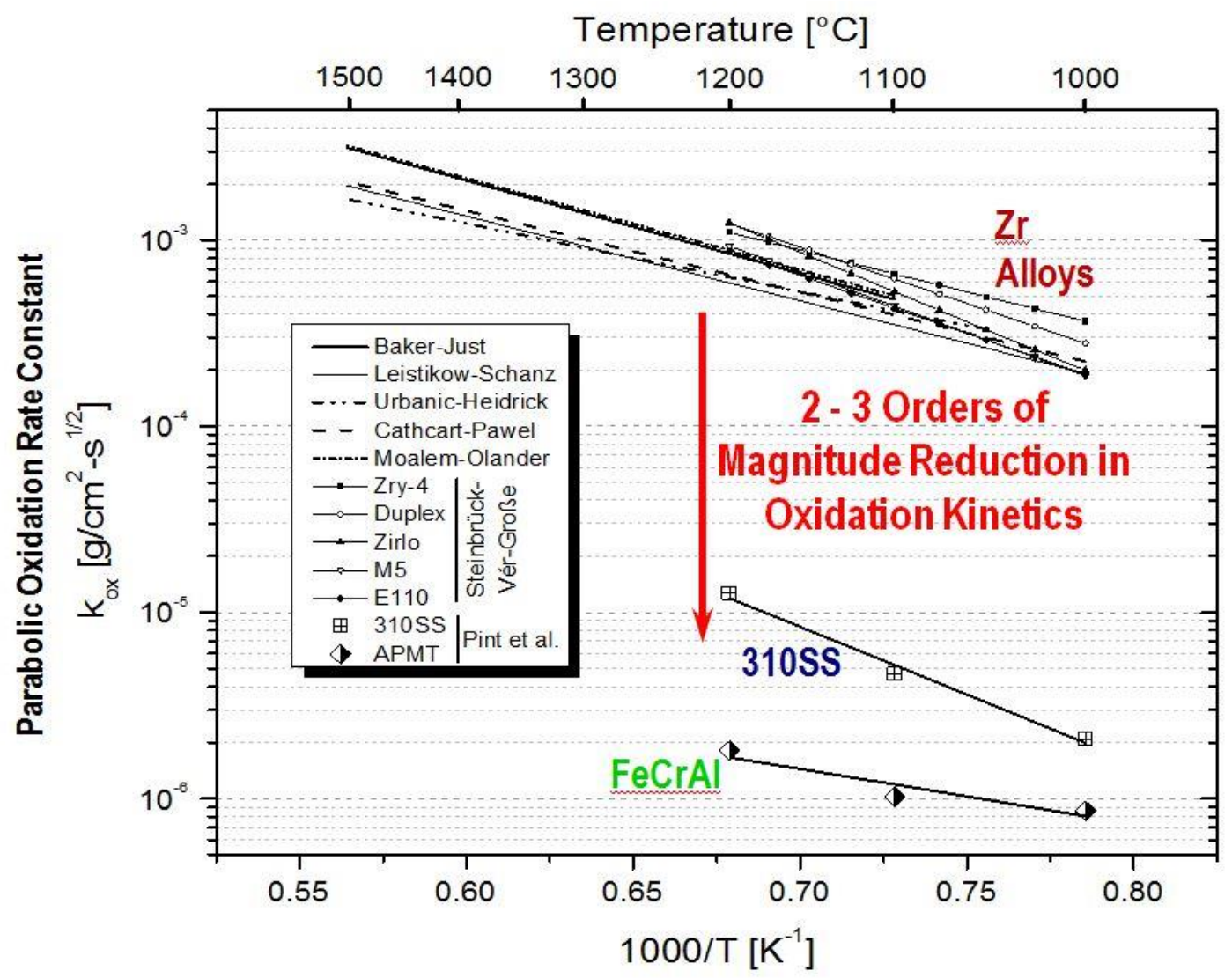

Figure 20 CORA/BWR-QUENCH simulation results for the $450 \mathrm{~mm}$ level in QUENCH-19.

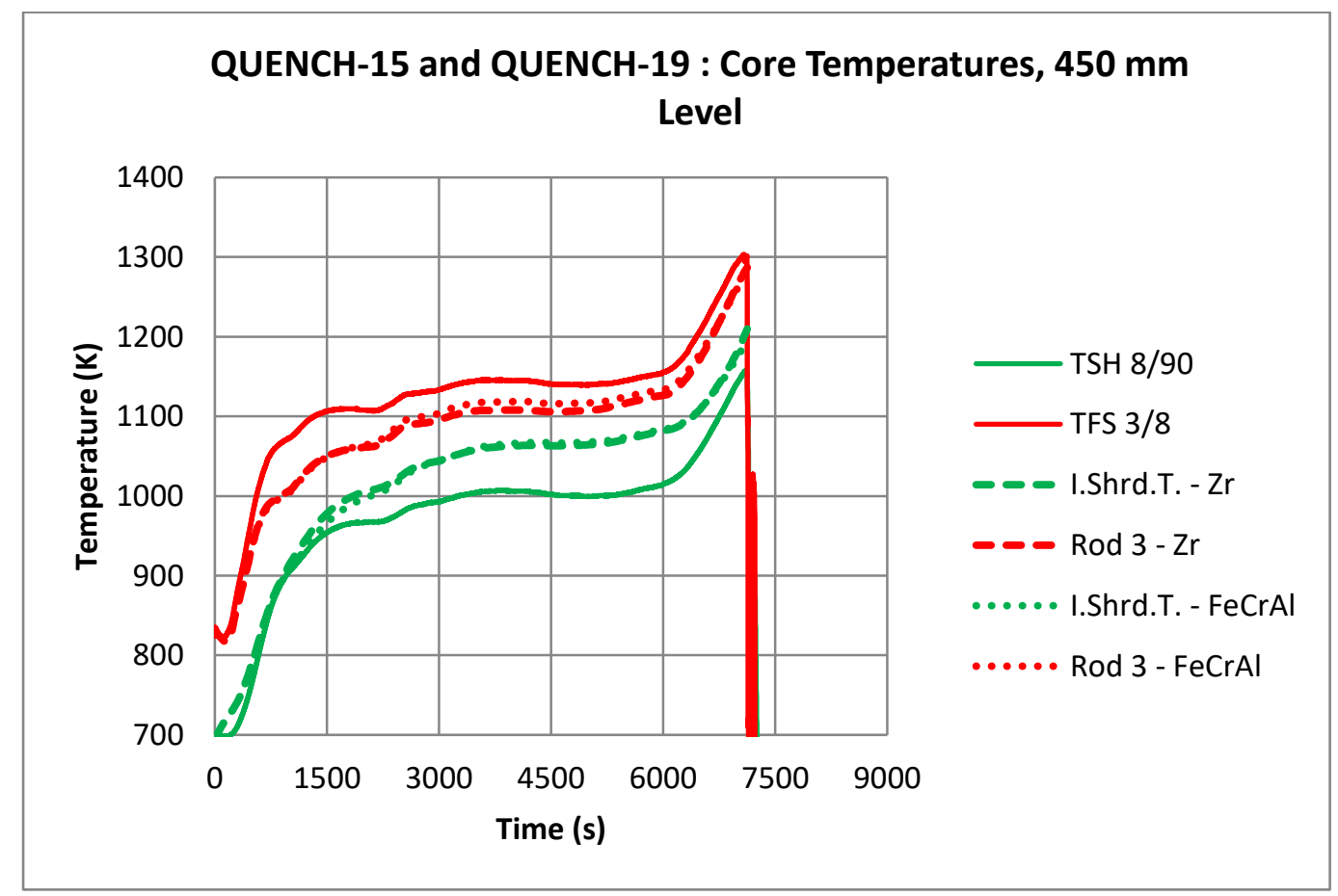


Figure 21 CORA/BWR-QUENCH simulation results for the 650 and $750 \mathrm{~mm}$ levels in QUENCH-19.
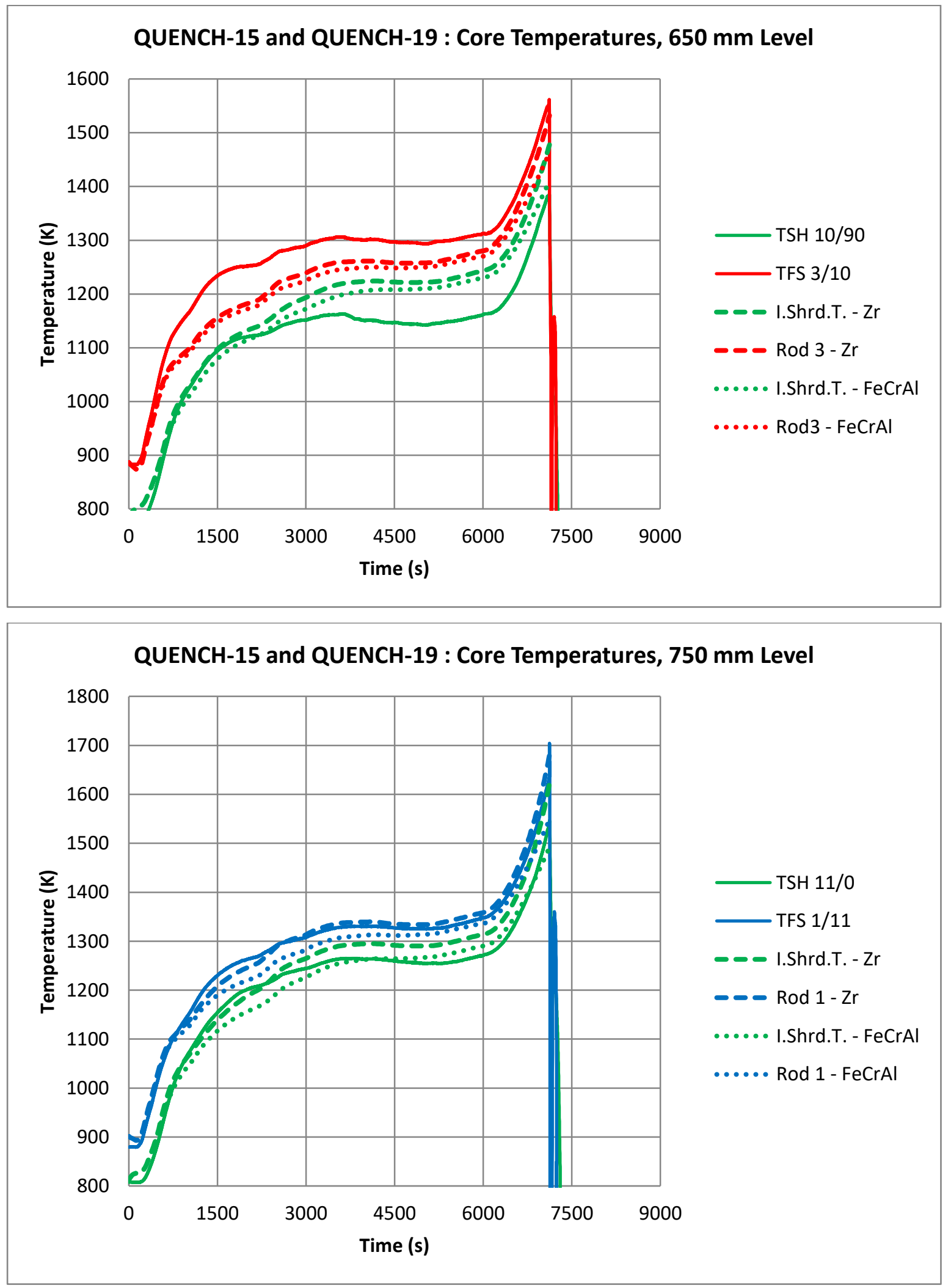
Figure 22 CORA/BWR-QUENCH simulation results for the 850 and $950 \mathrm{~mm}$ levels in QUENCH-19.
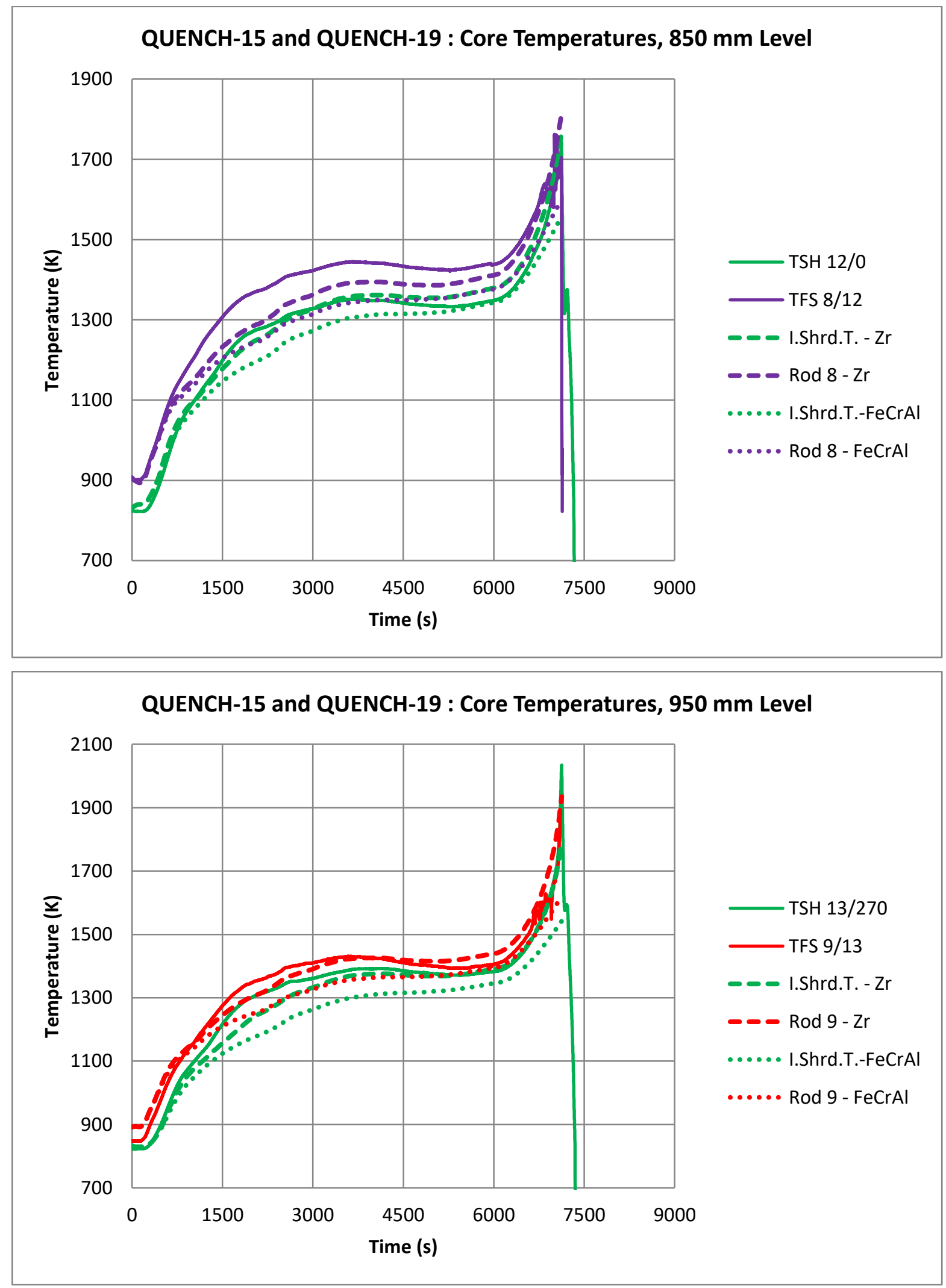
Figure 23 CORA/BWR-QUENCH simulation results for the 850 and $950 \mathrm{~mm}$ levels in QUENCH-19, expanded scale.
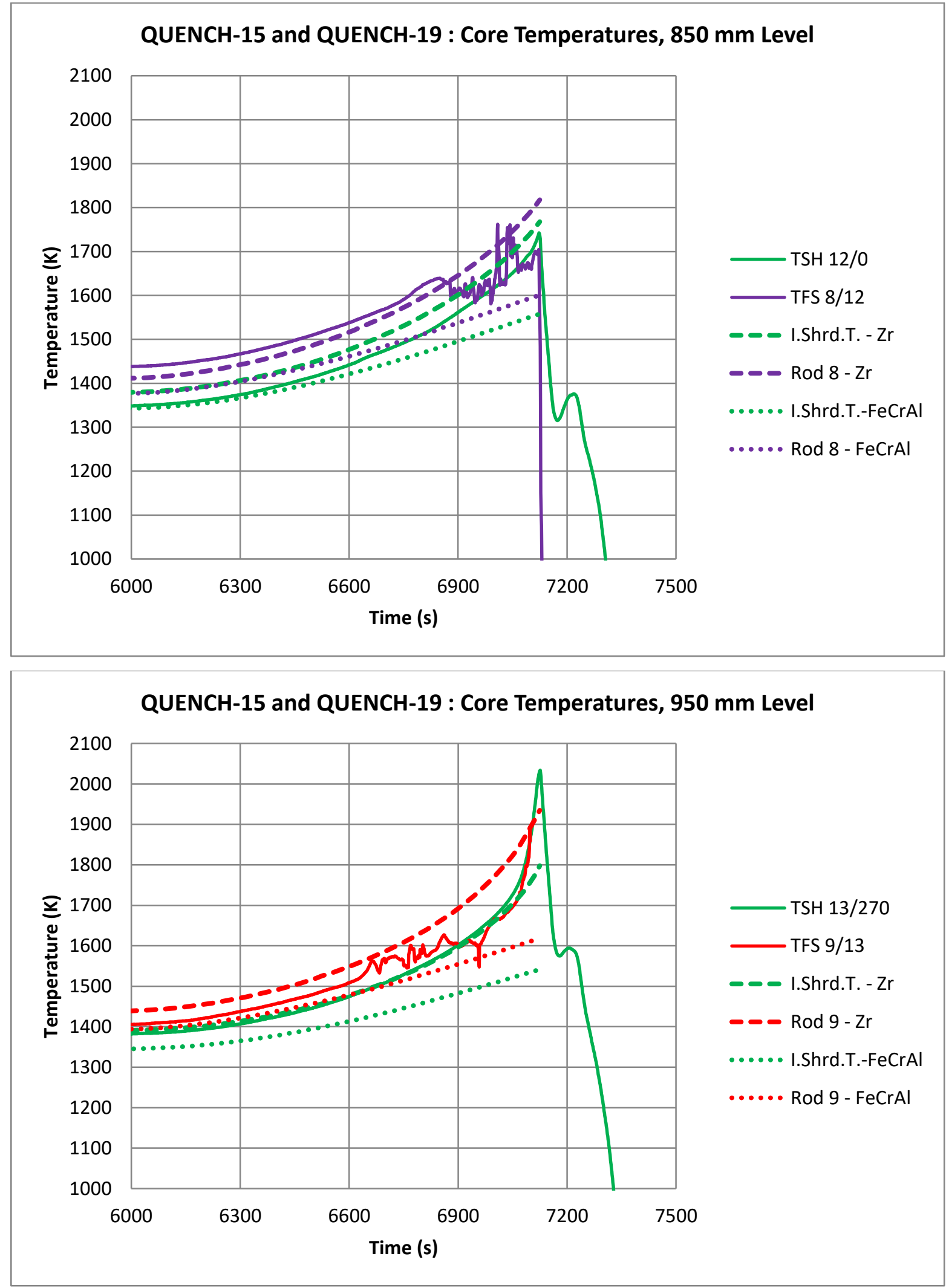
Figure 24 CORA/BWR-QUENCH simulations results for hydrogen generation in QUENCH-19.

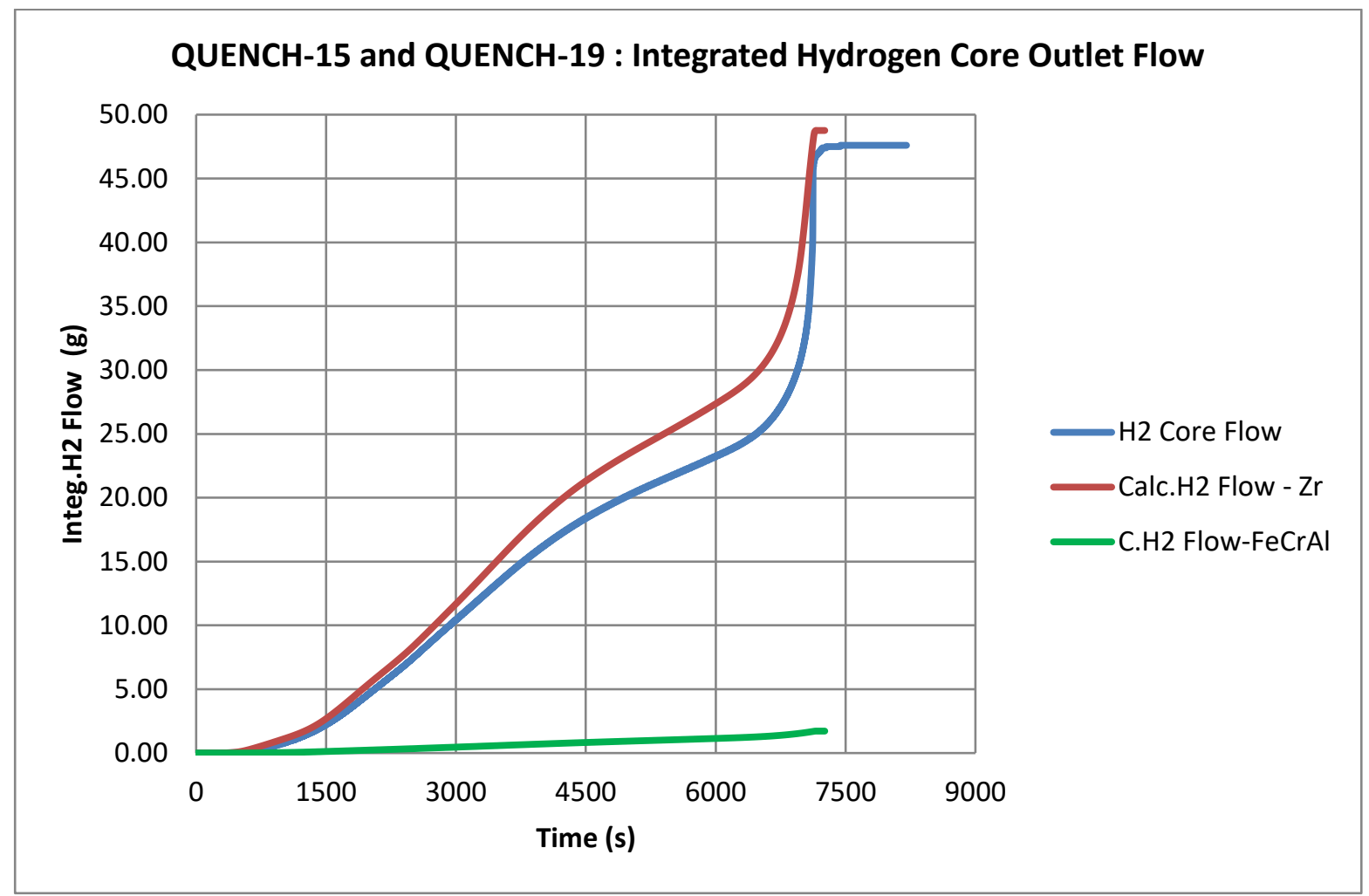




\section{CONCLUSIONS}

The CORA/BWR code successfully simulated the CORA-31 test, providing confidence in its current use. The code was successfully modified (CORA/BWR-QUENCH) to model the QUENCH test facility at KIT. This was demonstrated through simulation of the QUENCH-15 test. The code's temperature and hydrogen generation predictions closely follow the QUENCH-15 test data. A planned QUENCH-19 test will be conducted following the conditions of the QUENCH-15 test, except FeCrAl will be used for the structural materials (i.e., cladding, grids, and shroud). The CORA/BWR-QUENCH code was used to successfully model the planned QUENCH-19 test and to provide pre-test predictions. The oxidation kinetics and heat of oxidation for the structural materials were modified to reflect those of $\mathrm{FeCrAl}$ to simulate QUENCH-19. The simulation predicts the peak cladding temperature to be $1,620 \mathrm{~K}\left(\sim 1,347^{\circ} \mathrm{C}\right)$ for QUENCH-19, which is significantly lower than that of QUENCH-15 with ZIRLO ${ }^{\text {TM }}$ cladding. The predicted hydrogen generation is also significantly lower for the FeCrAl clad QUENCH-19 at $\sim 1.7 \mathrm{~g}$ when compared to QUENCH-15 at $\sim 48.8 \mathrm{~g}$. In general, the results were as expected given the much slower oxidation kinetics of FeCrAl alloys.

In the future, the quench phase of the QUENCH-15 and QUENCH-19 tests will be simulated. Additional code modifications will be required to accurately simulate the quench phenomena. Further work will refine the $\mathrm{FeCrAl}$ oxidation kinetics used by the code to reflect the most recent data available. Ultimately, the QUENCH-19 test will be conducted, providing experimental data for code validation, and more importantly, demonstrating the differences between FeCrAl clad (QUENCH-19) and zirconiumbased cladding (QUENCH-15) during postulated accident conditions.

\section{ACKNOWLEDGMENTS}

The authors thank Dr. Robert Salko and Dr. Aaron Wysocki at ORNL for their valuable technical reviews. The work presented in this paper was supported by the Advanced Fuels Campaign of the Fuel Cycle R\&D program in the Office of Nuclear Energy, US Department of Energy. 


\section{REFERENCES}

1. Haste, T., M. Steinbrück, M. Barrachin, O. de Luze, M. Grosse, J. Stuckert, “A comparison of core degredation phenomena in the CORA, QUENCH, Phebus SFD and Phebus FP experiments," NED, 283, p. 8-20, 2015.

2. Steinbrück, M., J. Stuckert, M. Große, L.Sepold, "Synopsis and outcome of the QUENCH experimental program," NED, 240, p.1714-1727, 2010.

3. Stuckert, J., M. Große, U. Stegmaier, M. Steinbrück, "Results of Severe Fuel Damage Experiment QUENCH15 with ZIRLO ${ }^{\mathrm{TM}}$ cladding tubes," Karlsruhe Institute of Technology, KIT-SR 7576, 2011.

4. Ott, L. J., S. Hagen, "Interpretation of the results of the CORA-33 dry core boiling water reactor test," NED, 167, p. 287-306, 1997.

5. Ott, L. J., Experiment-specific analyses in support of code development. No. CONF-901085-6. Oak Ridge National Lab., TN (USA), 1990.

6. Robb, K. R., M. Howell, L. J. Ott, "Parametric and experimentally informed BWR Severe Accident Analysis Utilizing FeCrAl - M3FT-17OR020205041," ORNL/SPR-2017/373, August 2017.

7. Ott , L. J., Description of the CORA BWR Experiment-Specific Code, letter report to the BWRCMP Program NRC Technical Monitor (Dr. R. W. Wright, Accident Evaluation Branch, Division of Systems Research, RES USNRC), ORNL/NRC/LTR-90/23, September 1990.

8. Ott, L. J., Post-Test Analyses of CORA BWR Experiments, letter report to the BWRCMP Program NRC Technical Monitor (Dr. R. W. Wright, Accident Evaluation Branch, Division of Systems Research, RES USNRC), ORNL/NRC/LTR-90/24, September 1990.

9. Ott, L. J., Post-Test Analyses of the CORA-16 and CORA-17 BWR Experiments, letter report to the BWRCMP Program NRC Technical Monitor (Dr. Ali Behbahani, Accident Evaluation Branch, Division of Systems Research, RES USNRC), ORNL/NRC/LTR-92/17, July 1992.

10. Ott, L. J., Report of Foreign Travel to KfK, Germany and Participation in the CORA-33 Experiment, letter report to the BWRCMP Program NRC Technical Monitor (Dr. Ali Behbahani, Accident Evaluation Branch, Division of Systems Research, RES USNRC), ORNL/NRC/LTR-92/28, November 1992.

11. Ott, L. J., Post-Test Analyses of the CORA-31 Slow Heatup BWR Experiment, letter report to the BWRCMP Program NRC Technical Monitor (Dr. Ali Behbahani, Accident Evaluation Branch, Division of Systems Research, RES USNRC), ORNL/NRC/LTR-92/29, December 1992.

12. Ott, L. J., Post-Test Analyses of the CORA-33 Dry Core BWR Experiment, letter report to the BWRCMP Program NRC Technical Monitor (Dr. Ali Behbahani, Accident Evaluation Branch, Division of Systems Research, RES USNRC), ORNL/NRC/LTR-93/21, August 1993.

13. Ott, L. J., Post-Test Analyses of the CORA-28 Preoxidized BWR Experiment, letter report to the BWRCMP Program NRC Technical Monitor (Dr. Ali Behbahani, Accident Evaluation Branch, Division of Systems Research, RES USNRC), ORNL/NRC/LTR-93/26, September 1993.

14. Sepold, L., S. Hagen, P. Hofmann, and G. Schanz, Behavior of BWR-type Fuel Elements with B4C/Steel Absorber Tested under Severe Fuel Damage Conditions in the CORA Facility, Forschungszentrum Karlsruhe, FZKA-7447, January 2009.

15. Zinkle, S., et al., Accident Tolerant Fuels for Light Water Reactors, NuMat2012, October 2012. 